Local cont rol of mitochondrial menbr ane pot ential, per meabi lity transition pore and react i ve oxygen speci es by cal ci um and cal modul i $n$ i $n$ rat vent ricul ar myocytes

\begin{tabular}{|l|l|}
\hline 著者 & Odagi r i Kei i chi \\
\hline $\begin{array}{l}\text { j our nal or } \\
\text { publ i cat i on ti t l e }\end{array}$ & Journal of Nol ecul ar and Cel I ul ar Car di ol ogy \\
\hline vol une & 46 \\
\hline nunber & 6 \\
\hline page r ange & $989-997$ \\
\hline year & $2009-06-01$ \\
\hline URL & ht t p: //hdl . handl e. net /10271/1898 \\
\hline
\end{tabular}




\title{
Local control of mitochondrial membrane potential, permeability transition pore and reactive oxygen species by calcium and calmodulin in rat ventricular myocytes
}

\author{
Keiichi Odagiri, Hideki Katoh, Hirotaka Kawashima, \\ Takamitsu Tanaka, Hayato Ohtani, Masao Saotome, \\ Tsuyoshi Urushida, Hiroshi Satoh and Hideharu Hayashi \\ Division of Cardiology, Internal Medicine III, \\ Hamamatsu University School of Medicine, \\ 1-20-1 Handayama, Higashi-ward, Hamamatsu 431-3192, Japan
}

RUNNING HEAD:

Calmodulin and mitochondrial function

KEYWORDS:

Calcium, Calmodulin, CaMKII, Mitochondria, Membrane potential, Mitochondrial permeability transition pore, Reactive oxygen species, Sarcoplasmic reticulum

\section{CORRESPONDENCE:}

Hideki Katoh MD. PhD,

Division of Cardiology, Internal Medicine III,

Hamamatsu University School of Medicine,

1-20-1 Handayama, Higashi-ward, Hamamatsu 431-3192, Japan

TEL: $+81-53-435-2267$

FAX: +81-53-434-2910

E-mail: hkatoh@hama-med.ac.jp 


\section{Abstract}

Calmodulin (CaM) and $\mathrm{Ca}^{2+} / \mathrm{CaM}-d e p e n d e n t$ protein kinase II (CaMKII) play

important roles in the development of heart failure. In this study, we evaluated the

effects of CaM on mitochondrial membrane potential $\left(\Delta \Psi_{\mathrm{m}}\right)$, permeability transition

pore (mPTP) and the production of reactive oxygen species (ROS) in permeabilized

myocytes; our findings are as follows. (1) CaM depolarized $\Delta \Psi_{\mathrm{m}}$ dose-dependently, but this was prevented by an inhibitor of CaM (W-7) or CaMKII (autocamtide 2-related inhibitory peptide (AIP)). (2) CaM accelerated calcein leakage from mitochondria, indicating the opening of mPTP, however this was prevented by AIP. (3) Cyclosporin A (an inhibitor of the mPTP) inhibited both CaM-induced $\Delta \Psi_{\mathrm{m}}$ depolarization and calcein leakage. (4) CaM increased mitochondrial ROS, which was related to $\Delta \Psi_{\mathrm{m}}$ depolarization and the opening of mPTP. (5) Chelating of cytosolic $\mathrm{Ca}^{2+}$ by BAPTA, the depletion of SR $\mathrm{Ca}^{2+}$ by thapsigargin (an inhibitor of SERCA) and the inhibition of mitochondrial $\mathrm{Ca}^{2+}$ uniporter by $\mathrm{Ru} 360$ attenuated the effects of $\mathrm{CaM}$ on mitochondrial function. (6) $\mathrm{CaM}$ accelerated $\mathrm{Ca}^{2+}$ extrusion from mitochondria. We conclude that $\mathrm{CaM} / \mathrm{CaMKII}$ depolarized $\Delta \Psi_{\mathrm{m}}$ and opened $\mathrm{mPTP}$ by increasing ROS production, and these effects were strictly regulated by the local increase in cytosolic $\mathrm{Ca}^{2+}$ concentration, 
initiated by $\mathrm{Ca}^{2+}$ releases from the SR. In addition, $\mathrm{CaM}$ was involved in the regulation of mitochondrial $\mathrm{Ca}^{2+}$ homeostasis. 


\section{Introduction}

In cardiac myocytes, intracellular $\mathrm{Ca}^{2+}$ and calmodulin $(\mathrm{CaM})$ have an important role in the regulation of cellular function $[1,2]$. After the binding of $\mathrm{Ca}^{2+}$, $\mathrm{CaM}$ activates $\mathrm{Ca}^{2+}$-calmodulin dependent protein kinase that has several isoforms, of which type II (CaMKII) is most abundant in the heart. Both CaM and CaMKII activate many cellular targets involved not only in $\mathrm{Ca}^{2+}$ regulation but also in cell metabolism, protein kinase, gene expression and cell proliferation, thus serving as ubiquitous second messengers $[1,3,4]$.

In addition to these physiological roles of $\mathrm{CaM} / \mathrm{CaMKII}$, recent studies demonstrated that $\mathrm{CaM} / \mathrm{CaMKII}$ is closely related to the onset and the development of heart diseases [3-5]. For example, CaMKII induces myocardial hypertrophy and remodeling by phsophorylating and exporting histone deacetylase (HDAC) from the cell nucleus $[4,6]$, causes deleterious effects in irreversible ischemia/reperfusion injury [7], and increases the probability of developing arrhythmias [3]. In human heart failure, CaMKII expression and CaMKII activity are increased and these changes correlate positively with the cardiac function of the patient $[1,4]$. 
In heart failure, the increased adrenergic activity contributes to the development of contractile dysfunction, and CaMKII is activated by $\beta_{1}$-adrenergic receptor $\left(\beta_{1} \mathrm{AR}\right)$. Activation of CaMKII during acute stimulation of $\beta_{1} \mathrm{AR}$ mediates the positive inotropic and relaxant effects of adenylate cyclase-cAMP-protein kinase A (PKA) [8]. In contrast, chronic $\beta_{1} \mathrm{AR}$ stimulation induces apoptosis but this was prevented not by PKA inhibitors but by CaMKII inhibitors, indicating the involvement of the activation of CaM/CaMKII, independently of PKA signaling [2]. Interestingly, the anti-apoptotic actions of CaMKII inhibition were mirrored by $\mathrm{SR}^{2{ }^{2+}}$ depletion induced by thapsigargin (TG), a potent antagonist of SR $\mathrm{Ca}^{2+}$-ATPase $[8,9]$.

Mitochondria are the central organelle for apoptotic cell death signaling, and mitochondrial $\mathrm{Ca}^{2+}$ overload occurs after persistent increases in cytosolic $\mathrm{Ca}^{2+}$ concentration $\left(\left[\mathrm{Ca}^{2+}\right]_{\mathrm{c}}\right)[10,11]$. An increase in mitochondrial $\mathrm{Ca}^{2+}$ concentration $\left(\left[\mathrm{Ca}^{2+}\right]_{\mathrm{m}}\right)$ depolarizes mitochondrial inner membrane potential $\left(\Delta \Psi_{\mathrm{m}}\right)$, produces ROS and triggers the mitochondrial permeability transition pore (mPTP) opening $[12,13]$, followed by the subsequent release of apoptogenic proteins into the cytosol [11]. Since $\mathrm{CaM} / \mathrm{CaMKII}$ translates $\mathrm{Ca}^{2+}$ signaling in cardiac myocytes, it is important to investigate how $\mathrm{CaM} / \mathrm{CaMKII}$ regulates mitochondrial function and apoptotic cell death. The purposes of this study were 1) to determine the effects of CaM and CaMKII on 
$\Delta \Psi_{\mathrm{m}}, \mathrm{mPTP}$ and ROS generation, 2) to clarify whether CaM-induced effects on

mitochondria are related to intracellular $\mathrm{Ca}^{2+}$ concentration and $\mathrm{SR} \mathrm{Ca}^{2+}$ contents, 3 ) to evaluate the effect of $\mathrm{CaM}$ on the regulation of mitochondrial $\mathrm{Ca}^{2+}$ homeostasis.

We found that CaM/CaMKII depolarized $\Delta \Psi_{\mathrm{m}}$, opened mPTP and increased ROS production. These effects of $\mathrm{CaM} / \mathrm{CaMKII}$ were strictly regulated by the local increase in cytosolic $\mathrm{Ca}^{2+}$ concentration, initiated by the $\mathrm{Ca}^{2+}$ releases from the SR. In addition, $\mathrm{CaM} / \mathrm{CaMKII}$ regulated mitochondrial $\mathrm{Ca}^{2+}$ homeostasis by accelerating $\mathrm{Ca}^{2+}$ extrusion via mitochondrial $\mathrm{Na}^{+} / \mathrm{Ca}^{2+}$ exchanger (mitoNCX). 


\section{Methods}

\subsection{Cell isolation and sarcolemmal membrane permeabilization}

This investigation conforms to the Guide for the Care and Use of Laboratory

Animals Published by the US National Institutes of Health (NIH Publication No. 85-23, revised 1996), and the Hamamatsu University School of Medicine Animal Care and Use Committee. The isolated myocytes were obtained from male Sprague-Dawley rats (250-350 g) as described previously $[14,15]$. In short, after the enzymatic dissociation, cells were once kept in a modified Kraft-Brühe solution, which contained (mM) 70 $\mathrm{KOH}, 40 \mathrm{KCl}, 20 \mathrm{KH}_{2} \mathrm{PO}_{4}, 3 \mathrm{MgCl}_{2}, 50$ glutamic acid, 10 glucose, $10 \mathrm{HEPES}$, and 0.5 EGTA (pH 7.4 with $\mathrm{KOH}$ ). Just before the experiments, the cells were placed in a chamber and perfused with a normal Tyrode solution, composed of (mM) $143 \mathrm{NaCl}, 5.4$ $\mathrm{KCl}, 0.5 \mathrm{MgCl}_{2}, 0.25 \mathrm{NaH}_{2} \mathrm{PO}_{4}, 1 \mathrm{CaCl}_{2}, 5.6$ glucose and 5 HEPES (pH 7.4 with $\mathrm{NaOH})$. For the permeabilization of sarcolemmal membrane, cells were perfused with saponin $(0.05 \mathrm{mg} / \mathrm{ml})$ in a $\mathrm{Ca}^{2+}$-free internal solution, which contained $(\mathrm{mM}) 50 \mathrm{KCl}, 80$ K-asparate, 4 Na-pyruvate, 20 HEPES, $3 \mathrm{MgCl}_{2}-6 \mathrm{H}_{2} \mathrm{O}$, $2 \mathrm{Na}_{2} \mathrm{ATP}, 3$ EGTA (pH 7.3 with $\mathrm{KOH}$ ). After the sarcolemmal membrane was permeabilized, the concentration of free calcium $\left(\left[\mathrm{Ca}^{2+}\right]_{\mathrm{c}}\right)$ in the internal solution was increased according to the experimental protocol. $\left[\mathrm{Ca}^{2+}\right]_{\mathrm{c}}$ was obtained by mixing EGTA and $\mathrm{CaCl}_{2}$, calculated 
with a computer program (WINMAXC, provided by Stanford University). All experiments were conducted at room temperature $\left(23^{\circ} \mathrm{C}\right)$ within 6 hours of cell isolation.

\subsection{Measurements with confocal imaging}

All measurements were performed with a laser scanning confocal microscope

(LSM 5 PASCAL, Karl-Zeiss) coupled to an inverted microscope (Axiovert 200M, Karl-Zeiss) with a $63 \times$ water-immersion objective lens ([NA] $=1.2$ : Karl-Zeiss).

Mitochondrial membrane potential was measured with a voltage fluorescent indicator, tetramethylrhodamine ethyl ester (TMRE). Saponin-permeabilized myocytes were loaded with TMRE $(10 \mathrm{nM})$ for 20 min by the continuous perfusion of TMRE in an internal solution. As a reference, an uncoupler, 2, 4-dinitorophenol (DNP, $100 \mu \mathrm{M}$ ), was applied at the end of the experiments. The opening of mPTP was evaluated by the calcein release from the mitochondrial matrix. As we described earlier $[15,16]$, the isolated myocytes were loaded with calcein-AM $(1 \mu \mathrm{M})$ for $30 \mathrm{~min}$, and then the sarcolemmal membrane was permeabilized to remove excessive cytoplasmic dyes. The generation of ROS was measured with the fluorescent indicator 2' 7'-dichlorofluorescin diacetate (DCF: $10 \mu \mathrm{M}$ ) or 6-carboxy-2' 7'-dichlorodihydrofluorescin diacetate, 
di(acetoxymethyl ester) (C-DCDHF-DA: $5 \mu \mathrm{M})$. For the measurement of DCF intensity, after the permeabilzation of the membrane, myocytes were continuously perfused with $10 \mu \mathrm{M}$ DCF [16]. In C-DCDHF-DA loaded myocyte, cells were loaded with C-DCDHF-DA for $30 \mathrm{~min}$ and then sarcolemmal membrane was permeabilized [17]. In the measurement of $\left[\mathrm{Ca}^{2+}\right]_{\mathrm{m}}$, myocytes were loaded with rhod-2-AM $(20 \mu \mathrm{M})$ for 30 min, and then the sarcolemmal membrane was permeabilized to remove the excessive cytosolic rhod-2 dyes [15].

TMRE and Rhod-2 were excited at $543 \mathrm{~nm}$ with a helium-neon laser, and the emission signals were collected through a $560 \mathrm{~nm}$ long-pass filter. Calcein was excited with an argon laser at $488 \mathrm{~nm}$ and emissions were collected through a $505 \mathrm{~nm}$ long pass filter. DCF and C-DCDHF-DA were excited with an argon laser at $514 \mathrm{~nm}$, and the emission signals were collected through a $530 \mathrm{~nm}$ long-pass filter. For quantitative analysis of the changes in fluorescent intensity, the identical regions of interest $(20 \times 20$ pixels) were monitored every 1-5 minutes. In the preliminary experiments, several ROIs $\underline{\text { were set in a single cell and fluorescent signals from each ROI were compared to }}$ examine spatial heterogeneity and there were small differences in the time courses of the changes in signal intensities among these ROIs. 


\subsection{Chemicals}

Calmodulin (CaM), autocamtide 2-related inhibitory peptide (AIP), cyclosporin A (CsA), 2, 4-dinitorophenol, 1, 2-Bis (2 aminophenoxy) ethane-N, N, N, N-tetraacetic acid tetrasodium salt (BAPTA) and thapsigargin (TG) were purchased from Sigma-Aldrich (St. Louis, Missouri, USA). W-7 hydrochloride (W-7), Ru360 and Trolox were purchased from Calbiochem-Novabiochem Corp. (La Jolla, California, USA). All fluorescent dyes were purchased from Molecular Probes (Eugene, OR, USA).

\subsection{Data analyses}

Data are presented as means $\pm \mathrm{SEM}$, and the number of cells or experiments is shown as n. Statistical analyses were performed using two-way ANOVA of repeated measurements, followed by Bonferroni test. A level of $\mathrm{p}<0.05$ was accepted as statistically significant. 


\section{Results}

\subsection{CaM depolarizes mitochondrial membrane potential $\left(\Delta \Psi_{m}\right)$ via mPTP opening}

To investigate the effects of $\mathrm{CaM} / \mathrm{CaMKII}$ on $\Delta \Psi_{\mathrm{m}}$, saponin-permeabilized myocytes were perfused with an internal solution, which contained $177 \mathrm{nM} \mathrm{Ca}^{2+}$ $\left(\left[\mathrm{Ca}^{2+}\right]_{\mathrm{c}}=177 \mathrm{nM}\right)$ and a voltage-sensitive fluorescent dye TMRE $(10 \mathrm{nM})$. Figure 1A shows the representative 2-D images of TMRE, which were obtained before, after 40 min administration, and after the washout of CaM. As shown in Figure 1B, 40 min perfusion of CaM $(10 \mathrm{nM})$ significantly depolarized $\Delta \Psi_{\mathrm{m}}(\mathrm{CaM} ; 53.4 \pm 3.7 \%$ of the baseline). When cells were pretreated with an inhibitor of CaM (W-7, $100 \mathrm{nM})$ or an inhibitor of CaMKII (AIP, $500 \mathrm{nM})$, application of CaM (10 nM) under the continuous presence of W-7 or AIP inhibited CaM-induced $\Delta \Psi_{\mathrm{m}}$ depolarization. It should be mentioned that the inhibitory effect of $\mathrm{W}-7$ was less than that of AIP. However, we were not able to use higher dose of $\mathrm{W}-7$, because in the preliminary experiment, $\mathrm{W}-7$ depolarized $\Delta \Psi_{\mathrm{m}}$ at the concentration higher than $500 \mathrm{nM}$. The effects of $\mathrm{W}-7$ and AIP indicated that CaM depolarized $\Delta \Psi_{\mathrm{m}}$ by activating cellular CaM/CaMKII. In Figure $1 \mathrm{C}$, TMRE intensities after 40 min perfusion of CaM (0.1 nM-1000 nM) and CaM (10 nM) with W-7 or AIP are summarized. CaM depolarized $\Delta \Psi_{\mathrm{m}}$ in a dose-dependent manner and inhibitors of $\mathrm{CaM}(\mathrm{W}-7 ; 80.2 \pm 1.2 \%$ of the baseline, $\mathrm{n}=10, \mathrm{p}<0.05$ versus $\mathrm{CaM}$ 
or AIP; $92.3 \pm 5.3 \%$ of the baseline, $\mathrm{n}=6, \mathrm{p}<0.05$ versus $\mathrm{CaM}$ ) attenuated the CaM-induced $\Delta \Psi_{\mathrm{m}}$ depolarization.

Since the opening of mPTP depolarizes $\Delta \Psi_{\mathrm{m}}[18]$, we investigated the effects of an mPTP inhibitor, cyclosporin A (CsA, $200 \mathrm{nM})$ on the CaM-induced depolazization of $\Delta \Psi_{\mathrm{m}}$. Pretreatment of myocytes with CsA (200 nM, for $\left.5 \mathrm{~min}\right)$ significantly attenuated CaM-induced $\Delta \Psi_{\mathrm{m}}$ depolarization $(\mathrm{CsA} ; 92.5 \pm 4.7 \%$ of the baseline, $\mathrm{n}=9, \mathrm{p}<0.05$ versus $\mathrm{CaM}$; Figure 1D) suggesting that $\mathrm{CaM} / \mathrm{CaMKII}$ depolarized $\Delta \Psi_{\mathrm{m}}$ in a CsA-sensitive manner.

We have previously reported that the permeabilization of myocytes after the loading of calcein-AM enabled localization of fluorescent calcein in mitochondria and that calcein signal reduced when the mPTP opened $[15,16]$. By using this method, the effects of CaM on the mPTP opening were examined. Figure 2A shows the representative 2-D images of calcein, recorded before and after the perfusion of CaM. As shown in Figure 2B, CaM significantly decreased calcein intensity compared with the control (CaM; $73.5 \pm 1.9 \%$ of the baseline, $\mathrm{n}=16, \mathrm{p}<0.05$ versus CTL; $90.1 \pm$ $2.9 \%$ of the baseline, $\mathrm{n}=18)$ and this effect was inhibited by CsA $(\mathrm{CsA} ; 88.8 \pm 1.9 \%$ of the baseline, $\mathrm{n}=8, \mathrm{p}<0.05$ versus CTL). When cells were preincubated with AIP and $\mathrm{CaM}$ was applied in the presence of AIP, the CaM-induced calcein leakage from 
mitochondria was inhibited by AIP $(83.6 \pm 1.5 \%$ of the baseline, $\mathrm{n}=12, \mathrm{p}<0.05$ versus $\mathrm{CaM}$ ). These results indicated that the activation of $\mathrm{CaM} / \mathrm{CaMKII}$ opened the $\mathrm{mPTP}$.

\subsection{CaM generates ROS which opens MPTP}

Mitochondria are one of the major sources for the generation of ROS, which is a key inducer of the mPTP [13]. To investigate whether CaM increases ROS generation, cells were loaded with a ROS sensitive dye, DCF [16] or C-DCDHF-DA [17]. The 2-D images of DCF (upper) and C-DCDHF-DA (bottom) obtained before and after the perfusion of $\mathrm{CaM}$ are shown in Figure 3A. As shown in Figure 3B, the DCF signal increased to $8.4 \pm 0.7$ fold of the baseline $(n=15, \mathrm{p}<0.05$ versus control) after the perfusion of CaM, and this CaM-induced DCF elevation was inhibited by a ROS scavenger Trolox $(100 \mu \mathrm{M})(1.8 \pm 0.5$ fold of the baseline, $\mathrm{n}=6, \mathrm{p}<0.05$ versus $\mathrm{CaM})$. Since DCF constantly existed in the internal solution and could respond to cytosoic ROS (possibly leaked out from mitochondrial matrix), we used acetoxymetyl form of DCF (C-DCDHF-DA) and selectively loaded mitochondria to clarify the site of ROS generation. In Figure 3C, CaM gradually increased the C-DCDHF-DA signal to $3.0 \pm$ 0.4 fold of the baseline ( $n=5, \mathrm{p}<0.05$ versus control), and Trolox $(100 \mu \mathrm{M})$ inhibited CaM-induced C-DCDHF-DA elevation $(1.4 \pm 0.1$ fold of the baseline, $\mathrm{n}=8, \mathrm{p}<0.05$ 
versus CaM). Pretreatment of AIP attenuated the increases in C-DCDHF-DA by CaM (AIP; $1.1 \pm 0.1$ fold of the baseline, $\mathrm{n}=8, \mathrm{p}<0.05$ versus CaM). These results indicate that ROS generated mainly in the mitochondrial matrix. When cells were pretreated with CsA, CaM-induced ROS generation was partially reduced $(1.9 \pm 0.1$ fold of the baseline, $\mathrm{n}=9, \mathrm{p}<0.05$ versus CaM, Figure 3D).

Next, we investigated the possible links between CaM-induced ROS generation, $\Delta \Psi_{\mathrm{m}}$ depolarization, and the mPTP opening. As shown in Figures $3 \mathrm{E}$ and $3 \mathrm{~F}$, pretreatment of Trolox prevented CaM-induced $\Delta \Psi_{\mathrm{m}}$ depolarization $(81.7 \pm 3.5 \%$ of the baseline, $\mathrm{n}=8, \mathrm{p}<0.05$ versus $\mathrm{CaM})$ and $\mathrm{CaM}$-induced calcein leakage $(87.2 \pm 1.3 \%$ of the baseline, $\mathrm{n}=11, \mathrm{p}<0.05$ versus $\mathrm{CaM}$ ). These data suggested that $\mathrm{CaM} / \mathrm{CaMKII}$ induced opening of $\mathrm{mPTP}$ and depolarization of $\Delta \Psi_{\mathrm{m}}$ were related to ROS generated in the mitochondrial matrix.

\subsection{CaM, intracellular $\mathrm{Ca}^{2+}$, and mitochondrial function}

In the following series of experiments, the involvement of $\mathrm{Ca}^{2+}$ in the effects of CaM was examined. When cells were exposed to CaM $(10 \mathrm{nM})$ with a nominal $\mathrm{Ca}^{2+}$-free $\left(\left[\mathrm{Ca}^{2+}\right]_{\mathrm{c}}=0 \mathrm{nM}\right)$ or a $\left[\mathrm{Ca}^{2+}\right]_{\mathrm{c}}=177 \mathrm{nM}$ internal solutions for $40 \mathrm{~min}$, there were no differences in CaM-induced depolarization of $\Delta \Psi \mathrm{m}$ between the two groups. $(0$ 
$\mathrm{nM} \mathrm{Ca}^{2+} ; 56.0 \pm 6.0 \%$ of the baseline, $\mathrm{n}=13,177 \mathrm{nM} \mathrm{Ca}^{2+} ; 53.4 \pm 3.7 \%$ of the baseline, $\mathrm{n}=9$, Figure 4A solid bars). When BAPTA $(5 \mathrm{mM})$ was added to the solution for the complete chelating of $\mathrm{Ca}^{2+}$, the CaM-induced $\Delta \Psi_{\mathrm{m}}$ depolarization was attenuated $(85.0$ $\pm 2.4 \%$ of the baseline, $\mathrm{n}=17, \mathrm{p}<0.05$ versus $177 \mathrm{nM} \mathrm{Ca}^{2+}$, Figure $\left.4 \mathrm{~A}\right)$. It was also shown that BAPTA eliminated CaM-induced calcein leakage from mitochondria $(92.4 \pm$ $1.5 \%$ of the baseline, $\mathrm{n}=9, \mathrm{p}<0.05$ versus $177 \mathrm{nM} \mathrm{Ca}^{2+}$, Figure $4 \mathrm{~B}$ ) and ROS generation by CaM $\left(3.4 \pm 0.2\right.$ fold of the baseline, $\mathrm{n}=7, \mathrm{p}<0.05$ versus $177 \mathrm{nM} \mathrm{Ca}^{2+}$, Figure 4C). These results indicated that at least sub-nanomolar intracellular $\mathrm{Ca}^{2+}$ is required for the activation of $\mathrm{CaM} / \mathrm{CaMKII}$, which leads to $\mathrm{CaM}$-induced mitochondrial ROS generation, the mPTP opening, and $\triangle \Psi \mathrm{m}$ depolarization.

\subsection{Sarcoplasmic reticulum $\mathrm{Ca}^{2+}$ and the effect of CaM on mitochondrial function}

Previous studies reported a cross-talk of $\mathrm{Ca}^{2+}$ signaling between SR and mitochondria [10]. We next investigated the role of $\mathrm{Ca}^{2+}$ releases from the $\mathrm{SR}$ on the effects of CaM. When cells were pretreated with thapsigargin (TG; $10 \mu \mathrm{M})$ for $15 \mathrm{~min}$ in a nominal $\mathrm{Ca}^{2+}$-free internal solution, the $\mathrm{SR} \mathrm{Ca}^{2+}$ content was completely depleted (assessed by $\mathrm{SR} \mathrm{Ca}^{2+}$ release with caffeine, data not shown). The application of CaM in the continuous presence of TG abolished the effects of CaM on $\Delta \Psi_{\mathrm{m}}$ (Figure $5 \mathrm{~A}, 85.0 \pm$ 
$2.4 \%$ of the baseline, $\mathrm{n}=16, \mathrm{p}<0.05$ versus without $\mathrm{TG}, \mathrm{n}=13$ ). TG also attenuated both CaM-induced calcein leakage from mitochondria $(89.1 \pm 3.2 \%$ of the baseline, $\mathrm{n}=$ $11, \mathrm{p}<0.05$ versus without TG, $\mathrm{n}=15$, Figure $5 \mathrm{~B})$ and ROS generation by CaM $(2.9 \pm$ 0.2 fold of the baseline, $p<0.05$ versus without $T G, n=5$, Figure $5 C$ ), indicating that the $\mathrm{SR} \mathrm{Ca}^{2+}$ releases are required to activate $\mathrm{CaM} / \mathrm{CaMKII}$ and to depolarize $\Delta \Psi_{\mathrm{m}}$. CaM-induced depolarization of $\Delta \Psi_{\mathrm{m}}$ was also inhibited when the $\mathrm{SR} \mathrm{Ca}^{2+}$ release was inhibited by ryanodine (supplemental Figure 1A). In contrast, CaM-induced $\Delta \Psi_{\mathrm{m}}$ depolarization was enhanced in the presence of caffeine $(1 \mathrm{mM})$, which facilitated SR $\mathrm{Ca}^{2+}$ release (supplemental Figure 1B). As demonstrated above, (Figures 4A-C), in the nominal $\mathrm{Ca}^{2+}$-free internal solution $\left(\left[\mathrm{Ca}^{2+}\right]_{\mathrm{c}}=0 \mathrm{nM}\right.$, without BAPTA), CaM depolarized $\Delta \Psi_{\mathrm{m}}$ as much as that observed in the $177 \mathrm{nM} \mathrm{Ca}^{2+}$ solution. In addition, neither the calcein leakage from mitochondria nor the DCF elevation by CaM was abolished when cells were perfused with the nominal $\mathrm{Ca}^{2+}$-free internal solution. Taken together, it is suggested that the $\mathrm{SR} \mathrm{Ca}^{2+}$ load and the local $\mathrm{Ca}^{2+}$ release from the SR play a pivotal role in activating $\mathrm{CaM} / \mathrm{CaMKII}$ and altering mitochondrial function.

\subsection{The effects of CaM on mitochondrial function are related to mitochondrial $\mathrm{Ca}^{2+}$}


A very close coupling of the $\mathrm{SR} \mathrm{Ca}^{2+}$ release site and mitochondrial $\mathrm{Ca}^{2+}$ uptake within a highly restricted domain $[15,19,20]$ implies that $\mathrm{Ca}^{2+}$ released from SR could alter $\left[\mathrm{Ca}^{2+}\right]_{\mathrm{m}}$ and mitochondrial function. Since mitochondrial $\mathrm{Ca}^{2+}$ uptake depends mainly on a $\mathrm{Ca}^{2+}$ uniporter, we investigated the effect of $\mathrm{Ru} 360$, a specific inhibitor of mitochondrial $\mathrm{Ca}^{2+}$ uniporter, on $\mathrm{CaM}$-induced mitochondrial function. As shown in Figure 6A, the CaM-induced $\Delta \Psi_{\mathrm{m}}$ depolarization $\left(\left[\mathrm{Ca}^{2+}\right]_{\mathrm{c}}=177 \mathrm{nM}\right)$ was partially inhibited by $10 \mu \mathrm{M}$ Ru360 $(68.6 \pm 1.3 \%$ of the baseline, $\mathrm{n}=9, \mathrm{p}<0.05$ versus $\mathrm{CaM})$. It was also shown that both calcein leakage from mitochondria $(83.4 \pm 2.0 \%$ of the baseline, $\mathrm{n}=11, \mathrm{p}<0.05$ versus CaM, figure $6 \mathrm{~B})$ and the increase in DCF $(5.5 \pm 0.4$ fold of the baseline, $\mathrm{n}=10, \mathrm{p}<0.05$ versus $\mathrm{CaM}$, figure 6C) induced by $\mathrm{CaM}$ were partially attenuated by Ru360. These results indicate that mitochondrial $\mathrm{Ca}^{2+}$ uptake was involved in CaM-induced changes in mitochondrial function.

The opening and closing of $\mathrm{mPTP}$ are tightly regulated by mitochondrial matrix $\mathrm{Ca}^{2+}$ concentration $\left(\left[\mathrm{Ca}^{2+}\right]_{\mathrm{m}}\right)$, and an increase in $\left[\mathrm{Ca}^{2+}\right]_{\mathrm{m}}$ facilitates the opening of mPTP [11]. The inhibitory effects of Ru360 on CaM-induced alterations in mitochondrial function suggest that the regulation of $\left[\mathrm{Ca}^{2+}\right]_{\mathrm{m}}$ might be affected by CaM. To address this, we assessed $\left[\mathrm{Ca}^{2+}\right]_{\mathrm{m}}$ by using a $\mathrm{Ca}^{2+}$ sensitive fluorescent indicator, rhod-2-AM, and examined whether exogenous CaM affects $\left[\mathrm{Ca}^{2+}\right]_{\mathrm{m}}$. In Figure 7A, 2-D 
images of rhod- 2 before and after the application of $\mathrm{CaM}$ in a $\mathrm{Na}^{+}$-free internal solution are shown. Figure 7B demonstrates the summarized data of rhod-2 intensities after a 20 min perfusion of $\mathrm{CaM}(10 \mathrm{nM})$ under different conditions. Perfusion of $\mathrm{CaM}$ with an internal solution $\left(177 \mathrm{nM} \mathrm{Ca}^{2+}\right.$ plus $\left.6 \mathrm{mM} \mathrm{Na}^{+}\right)$slightly, but not significantly, increased $\left[\mathrm{Ca}^{2+}\right]_{\mathrm{m}}(110.6 \pm 3.5 \%$ of baseline, $\mathrm{n}=13)$. When the $\mathrm{Ca}^{2+}$ extrusion via mitoNCX was inhibited with a $\mathrm{Na}^{+}$-free $\left(\left[\mathrm{Na}^{+}\right]_{\mathrm{c}}=0 \mathrm{mM}\right)$ solution [15], $\left[\mathrm{Ca}^{2+}\right]_{\mathrm{m}}$ did not increase significantly. However, the application of $\mathrm{CaM}$ in the $\mathrm{Na}^{+}$-free and $177 \mathrm{nM} \mathrm{Ca}^{2+}$ solution increased rhod-2 intensity significantly (to $150.1 \pm 4.1 \%$ of baseline, $\mathrm{n}=14, \mathrm{p}$ $<0.05)$. It is likely that $\mathrm{CaM}$-induced elevation of $\left[\mathrm{Ca}^{2+}\right]_{\mathrm{m}}$ was cancelled out by the $\mathrm{Ca}^{2+}$ extrusion via mitoNCX. When $\mathrm{SR} \mathrm{Ca}^{2+}$ releases were abolished by TG, the increase in $\left[\mathrm{Ca}^{2+}\right]_{\mathrm{m}}$ by CaM in a $\mathrm{Na}^{+}$-free solution was eliminated $(101.9 \pm 3.8 \%$ of the baseline, $\mathrm{n}$ $=9, \mathrm{p}<0.05$ vs. CaM alone). These results implied that there was a CaM-mediated $\mathrm{Ca}^{2+}$ signaling between the SR and mitochondria and that $\mathrm{Ca}^{2+}$ released from the SR was immediately taken-up by neighboring mitochondria. Inhibition of mitochondrial $\mathrm{Ca}^{2+}$ uptake by Ru360 reduced rhod-2 intensity to $85.3 \pm 2.7 \%$ of baseline $(n=6$, Figure $7 \mathrm{C})$ and the application of $\mathrm{CaM}$ in the presence of Ru360 further reduced the rhod-2 intensity to $78.2 \pm 3.3 \%$ of the baseline, ( $<0.05$ vs Ru 360 alone, $n=6$ ). From these 
results, it is suggested that $\mathrm{CaM}$ could activate $\mathrm{NCX}$ and accelerate $\mathrm{Ca}^{2+}$ extrusion via NCX. 


\section{Discussion}

Apoptotic cell death has been implicated as a causative factor in the development of cardiac dysfunction, and mitochondrial dysfunction bas been shown to participate in the induction of apoptosis. In this study, we investigated the effects of $\mathrm{CaM} / \mathrm{CaMKII}$ on mitochondrial function and mitochondrial $\mathrm{Ca}^{2+}$ regulation in chemically-skinned cardiac myocytes, and found that 1) CaM/CaMKII accelerated ROS production, opened $\mathrm{mPTP}$, and depolarized $\left.\Delta \Psi_{\mathrm{m}}, 2\right)$ these effects of $\mathrm{CaM} / \mathrm{CaMKII}$ on mitochondrial function were regulated by the local increase in $\left[\mathrm{Ca}^{2+}\right]_{\mathrm{c}}$, which was established by the $\mathrm{Ca}^{2+}$ releases from closely located $\left.\mathrm{SR}, 3\right) \mathrm{Ca}^{2+}$ influx via $\mathrm{Ca}^{2+}$ uniporter is involved in the effects of $\mathrm{CaM}$ on mitochondrial function, and 4)

$\mathrm{CaM} / \mathrm{CaMKII}$ regulated mitochondrial $\mathrm{Ca}^{2+}$ homeostasis by accelerating $\mathrm{Ca}^{2+}$ extrusion via mitoNCX.

\subsection{The effects of CaM and CaMKII on mitochondrial function in permeabilized myocytes}

$\mathrm{CaM}$ is a ubiquitous $\mathrm{Ca}^{2+}$ binding protein and about half of the cellular CaM is associated with membranes, especially at Z-lines in cardiac myocytes. While the other half is mainly in the cytoplasm and the nucleus, $\mathrm{CaM}$ is also identified at mitochondria. 
Physiologically, the total concentration of $\mathrm{CaM}([\mathrm{CaM}])$ of cardiac myocytes is about 6 $\mu \mathrm{M}$, and free $[\mathrm{CaM}]$ was estimated to be less than $50 \mathrm{nM}[21,22]$. In this study, we investigated the effects of $\mathrm{CaM} / \mathrm{CaMKII}$ on mitochondrial function by applying $\mathrm{CaM}$ in permeabilized myocytes, where $\left[\mathrm{Ca}^{2+}\right]_{\mathrm{c}}$ is controlled, and intracellular architectures, such as a close contact between the SR and mitochondria, are minimally perturbed [15, 16, 19]. The spontaneous $\mathrm{Ca}^{2+}$ releases from the $\mathrm{SR}$ were observed as resting $\mathrm{Ca}^{2+}$ sparks in our experimental condition (supplemental Figure 2A-E). In the experiments using fluorescent dye conjugated $\mathrm{CaM}$, the wash-in of exogenous $\mathrm{CaM}$ after sarcolemmal permeabilization has two-phase components with time constants of 34 seconds and 15 minutes [23]. This is in good agreement with our results that the effects of exogenously-applied $\mathrm{CaM}$ on mitochondrial function appeared within several minutes.

In this study, we used fluorescent dyes to monitor the $\Delta \Psi_{\mathrm{m}}$, the opening $\mathrm{mPTP}$, and ROS generation and demonstrated that exogenously-applied CaM depolarized $\Delta \Psi_{\mathrm{m}}$ dose- dependently (Figure 1C), within the ranges of previously reported physiological free $[\mathrm{CaM}]$. It is also shown that $\mathrm{CaM}$ accelerated the formation of mitochondrial ROS and opened the mPTP. However, it should be considered that the decrease in TMRE signal might be overestimated and the increase in ROS signal might be underestimated, 
respectively, because the opening of mPTP could release dyes from mitochondria. Since CaM-induced opening of the mPTP and depolarization of $\Delta \Psi_{\mathrm{m}}$ were inhibited by Trolox (Figures $3 \mathrm{E}$ and $3 \mathrm{~F}$ ), CaM-induced depolarization of $\Delta \Psi_{\mathrm{m}}$ and the opening mPTP could be attributed, at least in part, to mitochondrial ROS generation.

Our results that an inhibitor of CaMKII attenuated the effects of $\mathrm{CaM}$ on mitochondrial function suggest that exogenously-applied CaM activated CaMKII as a downstream target in permeablized myocytes. These results are consistent with previous studies, which described that $\beta_{1} \mathrm{AR}$ stimulation provoked oxidative stress and that the inhibition of $\mathrm{CaM}$ or CaMKII protected cells from apoptosis by preventing the accumulation of ROS [24-26]. CaM/CaMKII-induced depolarization of $\Delta \Psi_{\mathrm{m}}$ reduces ATP supply, and this may disturb cellular homeostasis by dysfunctioning cellular ATP dependent processes, such as $\mathrm{SR} \mathrm{Ca}^{2+}$ uptake. Thus, the energy impairment, as well as mPTP opening and apoptotic signaling is critical for the cellular damage induced by

\section{$\mathrm{CaM} / \mathrm{CaMKII}$.}

Although the mechanisms by which CaM/CaMKII increased ROS generation are not clear, several hypotheses could be proposed. First, CaM-induced changes in $\left[\mathrm{Ca}^{2+}\right]_{\mathrm{m}}$ may have activated $\mathrm{Ca}^{2+}$-dependent dehydrogenases that transfer more electrons to the respiratory chain and stimulate oxidative phosphorylation. Second, 
phosphorylation of several proteins as the down stream targets of $\mathrm{Ca}^{2+}-\mathrm{CaM} / \mathrm{CaMKII}$, such as $\delta$ subunit of ATP-synthase and monoamine oxidase located in outer membrane of the mitochondria, might have influenced the rate of respiration and the subsequent production of ROS [27]. Since the reduction of antioxidant activity, such as by glutathione [28], has been reported in $\mathrm{Ca}^{2+}$-exposed mitochondria or in failing hearts, CaM-induced alteration of $\left[\mathrm{Ca}^{2+}\right]_{\mathrm{m}}$ homeostasis may also have affected oxidant buffering potential, and possibly contributed to the increase in the total amount of mitochondrial ROS. In our study, CaM increased mitochondrial ROS generation and CsA attenuated this effect of CaM (Figure 3D). This result might indicate CsA inhibited mitochondrial ROS-induced ROS release via an mPTP [29]. Further studies are needed to clarify the underlying mechanism of $\mathrm{CaM} / \mathrm{CaMKII-induced} \mathrm{ROS} \mathrm{generation.}$

\subsection{The effects of CaM and CaMKII on mitochondria are regulated by local $\mathrm{Ca}^{2+}$ signaling and $\mathrm{Ca}^{2+}$ influx.}

Our results demonstrated that the removal of $\mathrm{Ca}^{2+}$ from an internal solution (in the presence of EGTA) had no apparent impact on CaM-induced ROS generation, mPTP opening and $\Delta \Psi_{\mathrm{m}}$ depolarization, while the complete quenching of intracellular $\mathrm{Ca}^{2+}$ by BAPTA or the depletion of SR $\mathrm{Ca}^{2+}$ by TG abolished the effects of $\mathrm{CaM}$ on 
mitochondrial function. Inhibition of SR $\mathrm{Ca}^{2+}$ release by ryanodine $(100 \mu \mathrm{M})$ also abolished CaM-induced $\Delta \Psi_{\mathrm{m}}$ depolarization (supplemental Figure 1A). These suggest that the activation of $\mathrm{CaM} / \mathrm{CaMKII}$ is intrinsically insensitive to the bulk cytosol levels of $\left[\mathrm{Ca}^{2+}\right]$ and requires the high $\left[\mathrm{Ca}^{2+}\right]$ established by $\mathrm{Ca}^{2+}$ releases from the SR [30]. This is further supported by our data that CaM-induced $\Delta \Psi_{\mathrm{m}}$ depolarization was enhanced in the presence of caffeine $(1 \mathrm{mM})$, which facilitates the $\mathrm{SR} \mathrm{Ca}^{2+}$ releases (supplemental Figure 1B).

One consideration is whether $\mathrm{Ca}^{2+}$ release from the SR occurred in our experimental conditions, because $\mathrm{CaM}$ is known to inhibit $\mathrm{SR} \mathrm{Ca}^{2+}$ releasing channel (RyR) opening [1]. However, Guo et al have recently reported that CaM decreased resting $\mathrm{Ca}^{2+}$ spark frequency dose-dependently, and that half-inhibition was at $100 \mathrm{nM}$ $\mathrm{CaM}\left(\mathrm{K}_{0.5}\right)$ in permeabilized mice ventricular myocytes [31]. The concentration of CaM used in this study was relatively low compared to this value. Phosphorylation of RyR by CaMKII has been shown to increase $\mathrm{Ca}^{2+}$ leakage from the SR $[2,31,32]$ and the distribution of CaMKII in the SR [33] and the existence of an anchoring protein of CaMKII in the SR have been previously demonstrated [34]. Thus, the balance between the inhibitory effects of CaM on RyR and the activating effect of CaMKII on the opening probability of RyR may determine total $\mathrm{Ca}^{2+}$ released from the SR. 
Although there is a close contact between mitochondria and RyR, and

mitochondrial $\mathrm{Ca}^{2+}$ uptake plays a critical role for the $\mathrm{Ca}^{2+}$ signal transduction during the exposure to $\mathrm{CaM}$, this is not a solo mechanism for the effects of $\mathrm{CaM}$ on mitochondria, since the inhibition of $\mathrm{Ca}^{2+}$ uniporter resulted in a partial inhibition of the effects of CaM (Figures 6A, B, C). The CaM-binding site on the outer surface of mitochondria $[35,36]$ has been identified, and the CaM binding protein waspurified from the matrix of bovine mitochondria [37]. However, the distribution of CaMKII in mitochondrial membrane or matrix has not been reported. Taken together, there is a possibility that activated CaM directly affects mitochondria-located target proteins and induces functional alteration of mitochondria.

\subsection{CaM/CaMKII and mitochondrial $\mathrm{Ca}^{2+}$ homeostasis}

Transportation of $\mathrm{Ca}^{2+}$ into mitochondria depends primarily on the uniporter and the extrusion of $\mathrm{Ca}^{2+}$ from mitochondria is largely achieved by mitoNCX, and previous reports indicated that mitochondrial $\mathrm{Ca}^{2+}$ uptake through the uniporter was facilitated by CaM $[38,39]$. We observed only a slight increase in $\left[\mathrm{Ca}^{2+}\right]_{\mathrm{m}}$ after the application of $\mathrm{CaM}$ (Figures 7B). This might be due to the compensated $\mathrm{Ca}^{2+}$ extrusion from mitochondria via mitoNCX, because CaM increased $\left[\mathrm{Ca}^{2+}\right]_{\mathrm{m}}$ in a $\mathrm{Na}^{+}$-free internal 
solution, where $\left[\mathrm{Na}^{+}\right]_{\mathrm{c}}$ dependent $\mathrm{Ca}^{2+}$ efflux via mitoNCX was inhibited [15]. The increase in $\left[\mathrm{Ca}^{2+}\right]_{\mathrm{m}}$ was completely inhibited in TG-pretreated cells (Figure 7A). This also indicates that the cross-talk of $\mathrm{Ca}^{2+}$ signaling between $\mathrm{SR} \mathrm{Ca}^{2+}$ release and mitochondrial $\mathrm{Ca}^{2+}$ uptake was affected by CaM.

It is likely that $\mathrm{Ca}^{2+}$ seems to be extruded from mitochondria via mitoNCX even after the complete inhibition of an uniportor (Figure 7C), suggesting that CaM activated mitoNCX and enhanced $\mathrm{Ca}^{2+}$ efflux from mitochondria even at relatively low concentration of $\left[\mathrm{Ca}^{2+}\right]_{\mathrm{m}}$.

\subsection{Conclusion}

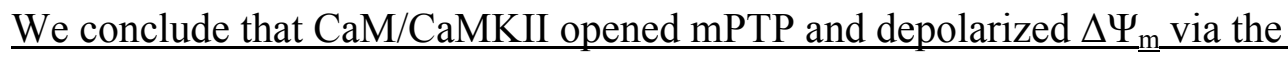
acceleration of ROS production in permeabilized rat ventricular myocytes and that these effects of CaM/CaMKII on mitochondria were related to high $\left[\mathrm{Ca}^{2+}\right]_{\mathrm{c}}$ established by $\underline{\mathrm{Ca}^{2+}}$ released from SR and to $\mathrm{Ca}^{2+}$ uptake by neighboring mitochondria. In addition, $\underline{\mathrm{CaM} / \mathrm{CaMKII} \text { regulated mitochondrial } \mathrm{Ca}^{2+} \text { homeostasis by increasing } \mathrm{Ca}^{2+} \text { influx and }}$ activating mitoNCX. 


\section{Acknowledgements}

This work was supported by Japan Grant in Aid 13670703 (to H.K) and 20590853 (to H.H) from the Japanese Ministry of Education, Culture, Sports, Science, and Technology. 


\section{Reference}

[1] Maier LS, Bers DM. Calcium, calmodulin, and calcium-calmodulin kinase II:

heartbeat to heartbeat and beyond. J Mol Cell Cardiol 2002; 34: 919-39.

[2] Wang W, Zhu W, Wang S, Yang D, Crow MT, Xiao RP, et al. Sustained

$\beta_{1}$-adrenergic stimulation modulates cardiac contractility by $\mathrm{Ca}^{2+} /$ calmodulin kinase

signaling pathway. Circ Res 2004; 95: 798-806.

[3] Grueter CE, Colbran RJ, Anderson ME. CaMKII, an emerging molecular

driver for calcium homeostasis, arrhythmias, and cardiac dysfunction. J Mol Med 2007;

85: 5-14.

[4] Zhang T, Miyamoto S, Brown JH. Cardiomyocyte calcium and

calcium/calmodulin-dependent protein kinase II: friends or foes? Recent Prog Horm

Res 2004; 59: 141-68. 
[5] Zhang R, Khoo MS, Wu Y, Yang Y, Grueter CE, Ni G, et al. Calmodulin kinase II inhibition protects against structural heart disease Nat Med. 2005r; 11: 409-17.

[6] Zhang T, Brown JH. Role of $\mathrm{Ca}^{2+} /$ calmodulin-dependent protein kinase II in cardiac hypertrophy and heart failure. Cardiovasc Res 2004; 63: 476-86.

[7] Vila-Petroff M, Salas MA, Said M, Valverde CA, Sapia L, Portiansky E, et al. CaMKII inhibition protects against necrosis and apoptosis in irreversible ischemia-reperfusion injury. Cardiovasc Res 2007; 73: 689-98.

[8] Zhu WZ, Wang SQ, Chakir K, Yang D, Zhang T, Brown JH, et al. Linkage of $\beta_{1}$-adrenergic stimulation to apoptotic heart cell death through protein kinase A-independent activation of $\mathrm{Ca}^{2+} /$ calmodulin kinase II. J Clin Invest 2003; 111: 617-25. 
[9] Yang Y, Zhu WZ, Joiner ML, Zhang R, Oddis CV, Hou Y, et al. Calmodulin kinase II inhibition protects against myocardial cell apoptosis in vivo. Am J Physiol Heart Circ Physiol 2006; 291: H3065-75.

[10] Hajnoczky G, Csordas G, Das S, Garcia-Perez C, Saotome M, Sinha Roy S, et al. Mitochondrial calcium signalling and cell death: approaches for assessing the role of mitochondrial $\mathrm{Ca}^{2+}$ uptake in apoptosis. Cell Calcium 2006; 40: 553-60.

[11] Crow MT, Mani K, Nam YJ, Kitsis RN. The mitochondrial death pathway and cardiac myocyte apoptosis. Circ Res 2004; 95: 957-70.

[12] Brookes PS, Yoon Y, Robotham JL, Anders MW, Sheu SS. Calcium, ATP, and ROS: a mitochondrial love-hate triangle. Am J Physiol Cell Physiol 2004; 287 :

C817-33. 
[13] Halestrap AP, McStay GP, Clarke SJ. The permeability transition pore complex: another view. Biochimie 2002; 84: 153-66.

[14] Katoh H, Nishigaki N, Hayashi H. Diazoxide opens the mitochondrial permeability transition pore and alters $\mathrm{Ca}^{2+}$ transients in rat ventricular myocytes.

Circulation 2002; 105: 2666-71.

[15] Saotome M, Katoh H, Satoh H, Nagasaka S, Yoshihara S, Terada H, et al.

Mitochondrial membrane potential modulates regulation of mitochondrial $\mathrm{Ca}^{2+}$ in rat ventricular myocytes. Am J Physiol Heart Circ Physiol 2005; 288: H1820-8.

[16] Tominaga H, Katoh H, Odagiri K, Takeuchi Y, Kawashima H, Saotome M, et al. Different effects of palmitoyl-L-carnitine and palmitoyl-CoA on mitochondrial function in rat ventricular myocytes. Am J Physiol Heart Circ Physiol 2008; 295 :

H105-12. 
[17] Satoh T, Sakai N, Enokido Y, Uchiyama Y, Hatanaka H. Free

radical-independent protection by nerve growth factor and Bcl-2 of PC12 cells from

hydrogen peroxide-triggered apoptosis. J Biochem 1996; 120: 540-6.

[18] Petronilli V, Cola C, Massari S, Colonna R, Bernardi P. Physiological effectors

modify voltage sensing by the cyclosporin A-sensitive permeability transition pore of

mitochondria. J Biol Chem 1993; 268: 21939-45.

[19] Lukyanenko V, Gyorke S. $\mathrm{Ca}^{2+}$ sparks and $\mathrm{Ca}^{2+}$ waves in saponin-permeabilized rat ventricular myocytes. J Physiol 1999; 521: 575-85.

[20] Gunter TE, Buntinas L, Sparagna G, Eliseev R, Gunter K. Mitochondrial calcium transport: mechanisms and functions. Cell Calcium 2000; 28: 285-96. 
[21] Maier LS, Ziolo MT, Bossuyt J, Persechini A, Mestril R, Bers DM. Dynamic changes in free Ca-calmodulin levels in adult cardiac myocytes. J Mol Cell Cardiol 2006; 41: 451-8.

[22] Ruben L, Goodman DB, Rasmussen H. Identification of calmodulin in mitochondria from rat liver: a possible role in regulation of the oligomycin sensitive ATPase. Ann N Y Acad Sci 1980; 356: 427-8.

[23] $\mathrm{Wu} X$, Bers DM. Free and bound intracellular calmodulin measurements in cardiac myocytes. Cell Calcium 2007; 41: 353-64.

[24] Huser CA, Davies ME. Calcium signaling leads to mitochondrial depolarization in impact-induced chondrocyte death in equine articular cartilage explants. Arthritis Rheum 2007; 56: 2322-34. 
[25] Jones HP, Ghai G, Petrone WF, McCord JM. Calmodulin-dependent

stimulation of the NADPH oxidase of human neutrophils. Biochim Biophys Acta 1982;

714: $152-6$.

[26] Broeke RT, Leusink-Muis T, Hilberdink R, Van Ark I, van den Worm E,

Villain M, et al. Specific modulation of calmodulin activity induces a dramatic

production of superoxide by alveolar macrophages. Lab Invest 2004; 84: 29-40.

[27] Andreyev AY, Kushnareva YE, Starkov AA. Mitochondrial metabolism of reactive oxygen species. Biochemistry (Mosc) 2005; 70: 200-14.

[28] Qin F, Shite J, Liang CS. Antioxidants attenuate myocyte apoptosis and improve cardiac function in CHF: association with changes in MAPK pathways. Am J Physiol Heart Circ Physiol 2003; 285: H822-32. 
[29] Zorov DB, Juhaszova M, Sollott SJ. Mitochondrial ROS-induced ROS release:

an update and review. Biochim Biophys Acta 2006; 1757: 509-17.

[30] Rizzuto R, Pinton P, Carrington W, Fay FS, Fogarty KE, Lifshitz LM, et al.

Close contacts with the endoplasmic reticulum as determinants of mitochondrial $\mathrm{Ca}^{2+}$

responses. Science 1998; 280: 1763-6.

[31] Guo T, Zhang T, Mestril R, Bers DM. $\mathrm{Ca}^{2+} /$ Calmodulin-dependent protein kinase II phosphorylation of ryanodine receptor does affect calcium sparks in mouse ventricular myocytes. Circ Res 2006; 99: 398-406.

[32] Curran J, Hinton MJ, Rios E, Bers DM, Shannon TR. $\beta$-adrenergic enhancement of sarcoplasmic reticulum calcium leak in cardiac myocytes is mediated by calcium/calmodulin-dependent protein kinase. Circ Res 2007; 100: 391-8. 
[33] Bilezikjian LM, Kranias EG, Potter JD, Schwartz A. Studies on

phosphorylation of canine cardiac sarcoplasmic reticulum by calmodulin-dependent

protein kinase. Circ Res 1981; 49: 1356-62.

[34] Damiani E, Sacchetto R, Salviati L, Margreth A. Two splice variants of

CaMKII-anchoring protein are present in the sarcoplasmic reticulum of rabbit

fast-twitch muscle. Biochem Biophys Res Commun 2003; 302: 73-83.

[35] Jurado LA, Chockalingam PS, Jarrett HW. Apocalmodulin. Physiol Rev 1999;

79: 661-82.

[36] Pardue RL, Kaetzel MA, Hahn SH, Brinkley BR, Dedman JR. The identification of calmodulin-binding sites on mitochondria in cultured $3 \mathrm{~T} 3$ cells. Cell

$1981 ; 23: 533-42$. 
[37] Hatase O, Tokuda M, Sharma RK, Wang JH, Green DE. Purification and characterization of the heat-stable calmodulin-binding protein from the matrix of bovine heart mitochondria. Biochem Biophys Res Commun 1983; 113: 633-7.

[38] Moreau B, Nelson C, Parekh AB. Biphasic regulation of mitochondrial $\mathrm{Ca}^{2+}$ uptake by cytosolic $\mathrm{Ca}^{2+}$ concentration. Curr Biol 2006; 16: 1672-7.

[39] Csordas G, Hajnoczky G. Plasticity of mitochondrial calcium signaling. J Biol Chem 2003; 278: 42273-82. 


\section{Figure Legends}
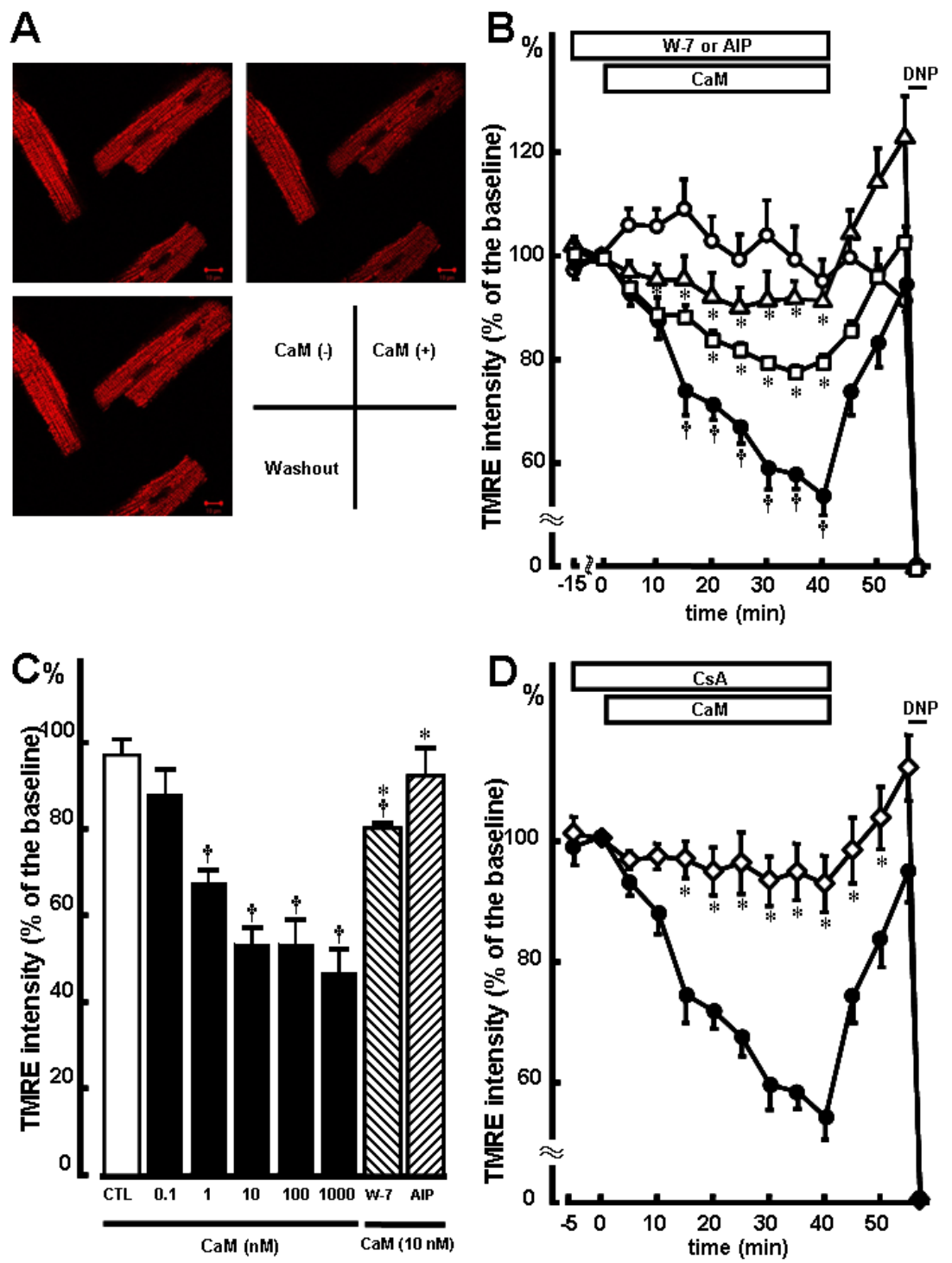

Figure 1, CaM depolarizes mitochondrial membrane potential.

(A) The 2-D images of TMRE, upper left; before CaM, upper right; after 40 min perfusion of CaM, and lower left; after the washout of CaM. (B) Time courses of the changes in TMRE intensity. Permeabilized myocytes were perfused with a $177 \mathrm{nM} \mathrm{Ca}^{2+}$ internal solution $\left(\left[\mathrm{Ca}^{2+}\right]_{\mathrm{c}}=177 \mathrm{nM}, \mathrm{O} ; \mathrm{n}=8\right)$, and then $\mathrm{CaM}(10 \mathrm{nM})$ was applied in the absence $(\bullet ; n=9)$ or presence of W-7 $(\square ; 100 \mathrm{nM}, \mathrm{n}=10)$ or $\operatorname{AIP}(\triangle ; 500 \mathrm{nM}, \mathrm{n}=6)$. In the W-7 or AIP-treated group, cells were pretreated with W-7 or AIP for $15 \mathrm{~min}$, and then CaM was applied with the presence of W-7 or AIP. As a reference, an uncoupler, DNP $(100 \mu \mathrm{M})$, was applied at the end of experiments. (C) The summarized data of TMRE intensity after 40 min perfusion with a control internal solution (CTL, $\mathrm{n}=8), \mathrm{CaM}(0.1 \mathrm{nM}-1000 \mathrm{nM}, \mathrm{n}=8)$, CaM plus W-7 ( $n=10)$, and CaM plus AIP $(n=6)$. (D) The same experimental protocol as (B) was conducted in the absence $(\bullet, n=9)$ or presence of CsA $(\diamond ; 200 \mathrm{nM}, \mathrm{n}=9)$. In the CsA-treated group, cells were pretreated with CsA for $5 \mathrm{~min}$, and then $\mathrm{CaM}(10 \mathrm{nM})$ was applied in the presence of CsA. Data are presented as the percentages of TMRE intensity before CaM application, and values are means \pm SEM. $* \mathrm{p}<0.05$ vs CaM, $\uparrow \mathrm{p}<0.05$ vs CTL by two-way ANOVA and Bonferroni test. 
A

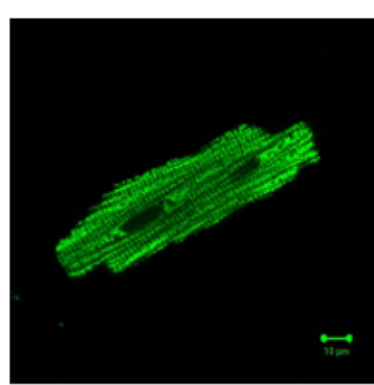

CaM (-)

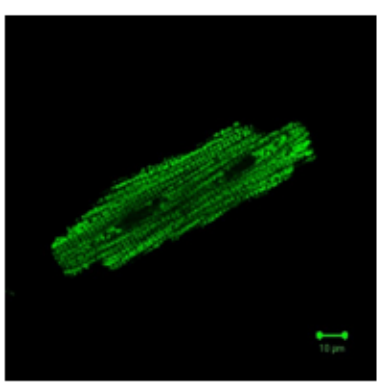

CaM (+)
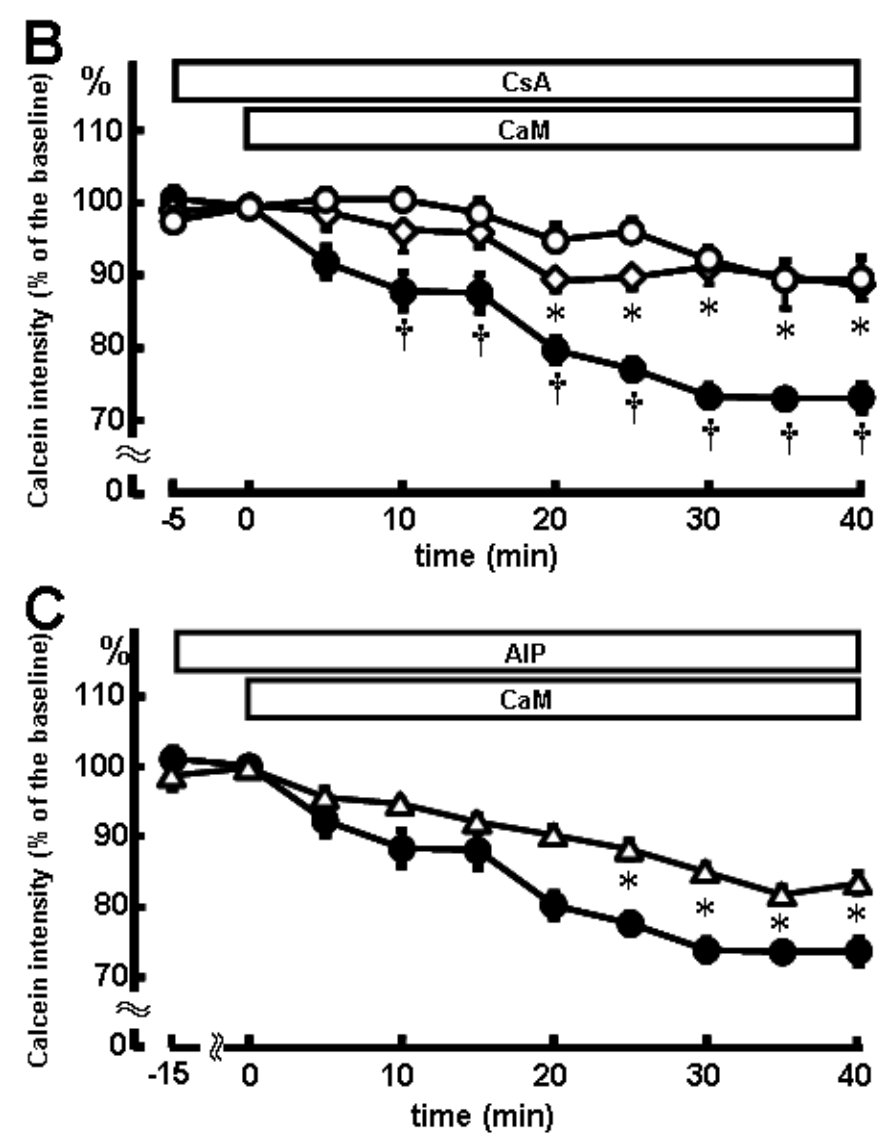

Figure 2, CaM opens mitochondrial permeability transition pore.

(A) The 2-D images of calcein, left; before CaM and right; after the perfusion of CaM. (B) Time courses of the changes in calcein intensity during the perfusion of a control internal solution $\left(O ;\left[\mathrm{Ca}^{2+}\right]_{\mathrm{c}}=177 \mathrm{nM}, \mathrm{n}=18\right), \mathrm{CaM}$ $(\bullet ; 10 \mathrm{nM}, \mathrm{n}=16)$, and CaM plus CsA $(\diamond ; 200 \mathrm{nM}, \mathrm{n}=8)$. In the CsA-treated group, cells were pretreated with CsA for $5 \mathrm{~min}$, and then CaM was applied in the presence of CsA. (C) the same experimental protocol as (B) was performed in the absence $(\bullet ; 10 \mathrm{nM}, \mathrm{n}=16)$ and presence of $\operatorname{AIP}(\triangle ; 500 \mathrm{nM}, \mathrm{n}=12)$. In the AIP-treated group, cells were pretreated AIP for $15 \mathrm{~min}$, and then CaM was applied in the presence of AIP. Data are presented as the percentages of calcein intensity before CaM application, and values are means \pm SEM. $*$ p $<0.05$ vs $\mathrm{CaM}, \uparrow \mathrm{p}<0.05$ vs control by two-way ANOVA and Bonferroni test. 

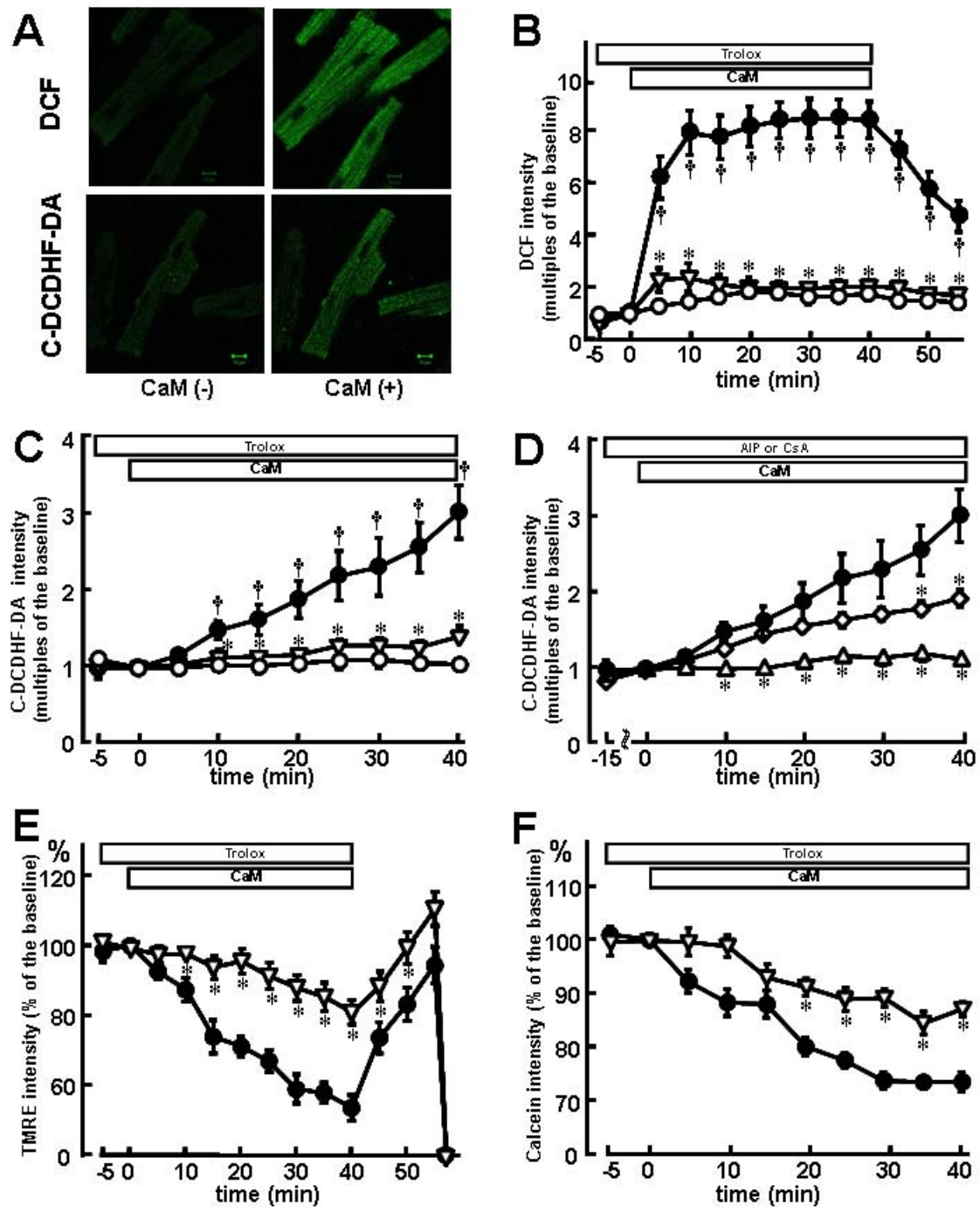

Figure 3, CaM increases mitochondrial ROS production.

(A) The 2-D images of DCF (upper) and C-DCDHF-DA (bottom). left; before CaM, right; after the perfusion of CaM for 40 min. (B) and (C) Time courses of changes in DCF (B) or C-DCDHF-DA (C) signals during and after the perfusion of $\mathrm{CaM}$ in the presence of ROS scavenger (Trolox). Cells were perfused with a control internal solution $(\mathrm{O}$; $\left.\left[\mathrm{Ca}^{2+}\right]_{\mathrm{c}}=177 \mathrm{nM}, \mathrm{n}=5-7\right), \mathrm{CaM}(\bullet ; 10 \mathrm{nM}, \mathrm{n}=7-15)$, and CaM plus Trolox $(\nabla ; 100 \mu \mathrm{M}, \mathrm{n}=6-8)$. In the Trolox-treated group, cells were pretreated with Trolox for $5 \mathrm{~min}$, and then CaM was applied in the presence of Trolox. Data are presented as multiples of the baseline before CaM application, and values are means \pm SEM. (D) Time courses of changes in C-DCDHF-DA signals during and after the perfusion of CaM in the presence of AIP or CsA. In the AIP or CsA-treated group, cells were preincubated with AIP $(\triangle, 500 \mathrm{nM}, \mathrm{n}=8)$, or $\operatorname{CsA}(\diamond, 200 \mathrm{nM}, \mathrm{n}=$ 9) for $15 \mathrm{~min}$, and then CaM was applied in the presence of AIP or CsA. Data are presented as multiples of the baseline before CaM application, and values are means \pm SEM. (E) and (F) Time courses of changes in TMRE (E) and calcein $(\mathrm{F})$ intensity during and after the perfusion of $\mathrm{CaM}$. The same experimental protocol as $\mathrm{B}$ or $\mathrm{C}$ was conducted to measure TMRE and calcein in the absence $(\bullet, \mathrm{n}=9-16)$ or presence of Trolox $(\nabla, 100 \mu \mathrm{M}, \mathrm{n}=8-11)$ in the $177 \mathrm{nM} \mathrm{Ca}^{2+}$ internal solution. Data are presented as the percentages of TMRE or calcein intensity before CaM application, and values are means \pm SEM. ${ }^{*} \mathrm{p}<0.05$ vs CaM, by two-way ANOVA and Bonferroni test. 

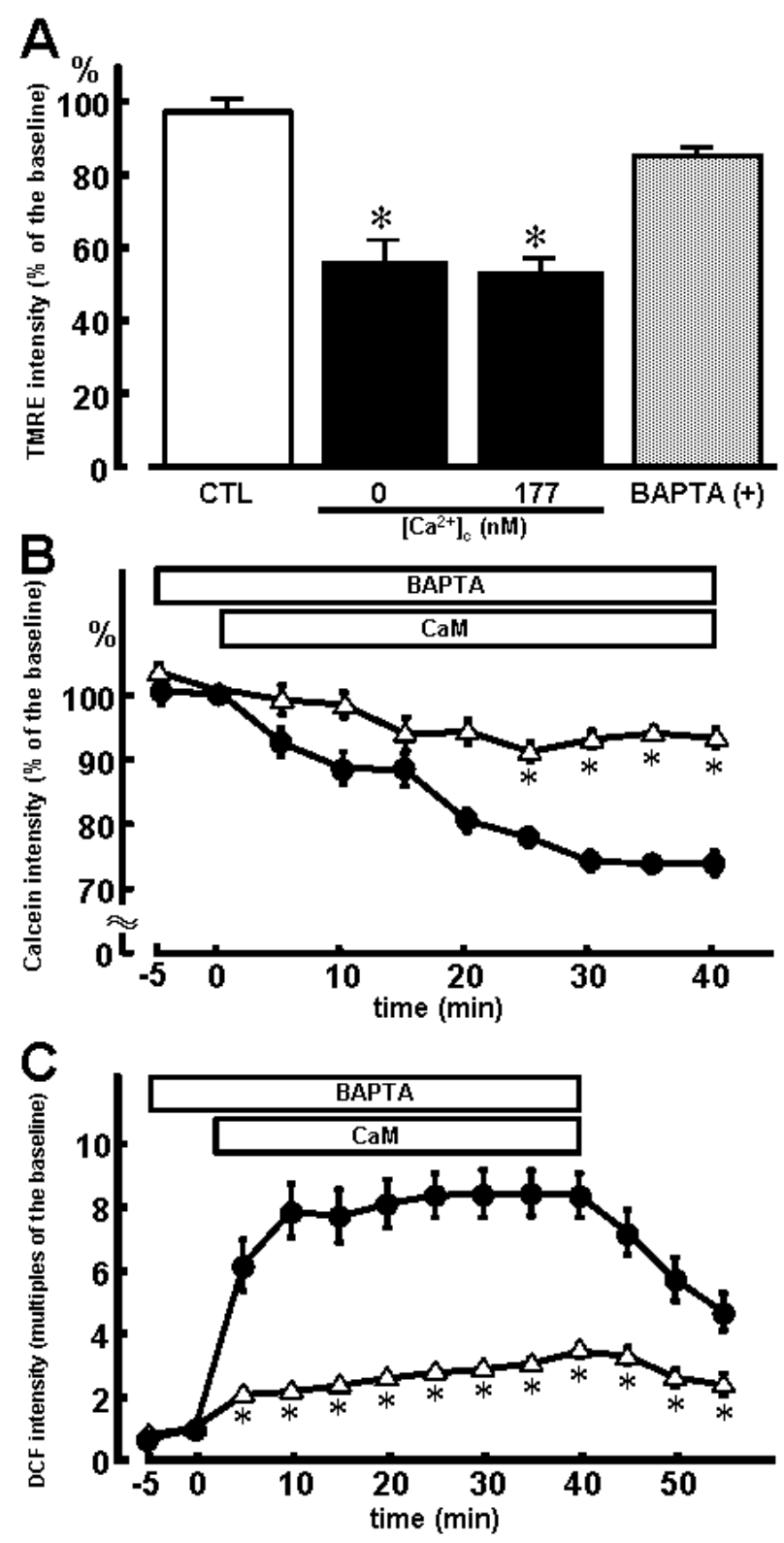

Figure 4, Intracellular $\mathrm{Ca}^{2+}$ is required for the effects of $\mathrm{CaM}$ on mitochondria.

(A) The summarized data of TMRE intensity after 40 min perfusion of $\mathrm{CaM}(10 \mathrm{nM})$ in the $\mathrm{Ca}^{2+}-\mathrm{free}\left(\left[\mathrm{Ca}^{2+}\right]_{\mathrm{c}}=0\right.$ $\mathrm{nM})$ internal solution with $(\mathrm{n}=17)$ or without BAPTA $(5 \mathrm{mM}, \mathrm{n}=13), 177 \mathrm{nM}(\mathrm{n}=9) \mathrm{Ca}^{2+}$ internal solution. Data are presented as the percentages of TMRE intensity before CaM application, and values are means \pm SEM. $*$ p $<0.05$ vs $\mathrm{Ca}^{2+}$-free internal solution with BAPTA, by two-way ANOVA and Bonferroni test.

(B) and (C): Time courses of changes in calcein (B) and DCF (C) signals by CaM with or without intracellular $\mathrm{Ca}^{2+}$. Cells were perfused with $\mathrm{CaM}(\bullet, \mathrm{n}=9-16)$ in the $177 \mathrm{nM} \mathrm{Ca}^{2+}$ internal solution $\left(\left[\mathrm{Ca}^{2+}\right]_{\mathrm{c}}=177 \mathrm{nM}\right)$ or CaM plus BAPTA in a $\mathrm{Ca}^{2+}$-free internal solution $(\triangle, 5 \mathrm{mM}, \mathrm{n}=7-17)$. Data are presented as the percentages of calcein intensity or multiples of DCF intensity before CaM application, and values are means \pm SEM. $* p<0.05$ vs CaM, by two-way ANOVA and Bonferroni test. 

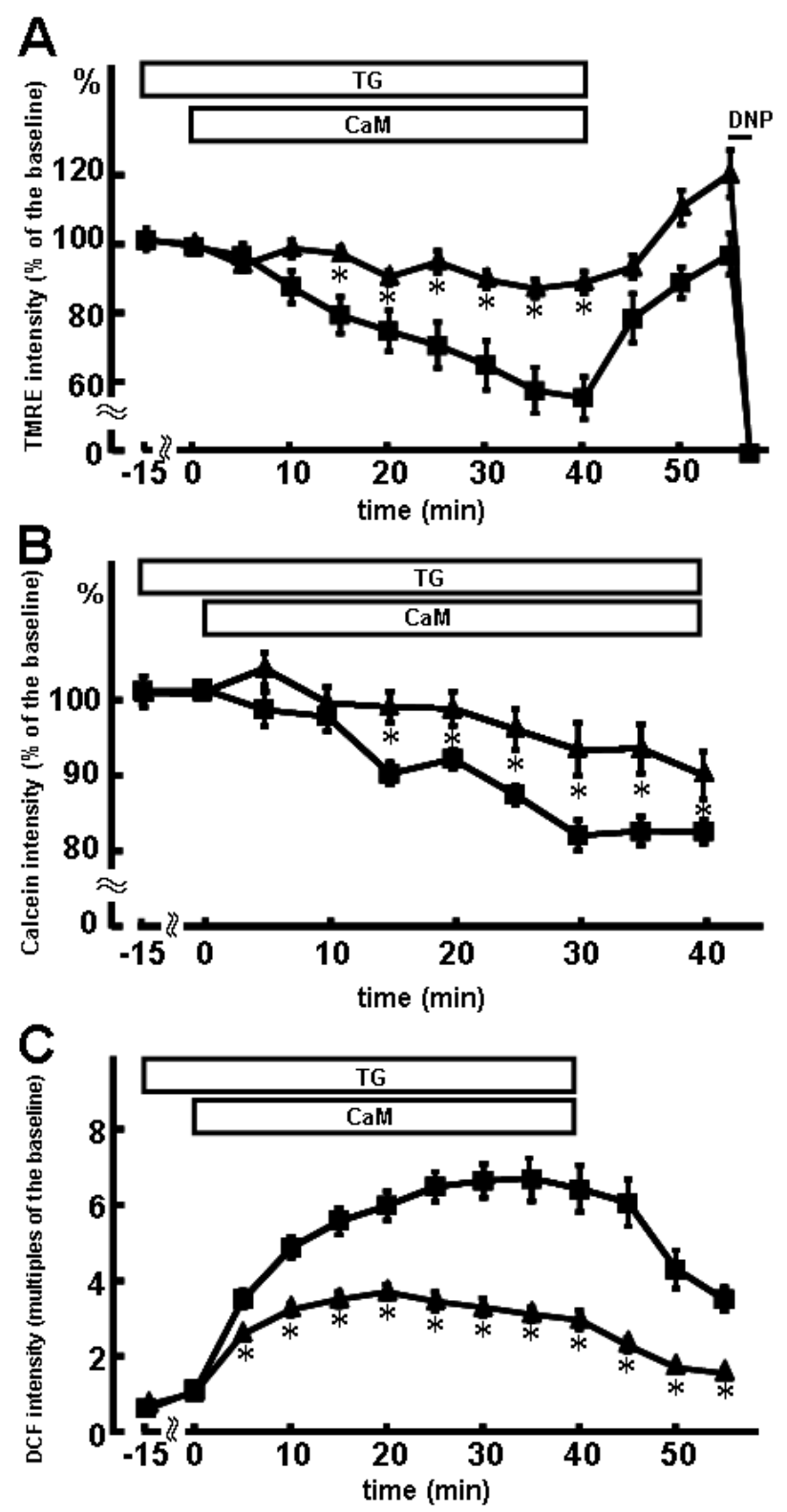

Figure 5, $\mathrm{SR} \mathrm{Ca}^{2+}$ is involved for the effects of $\mathrm{CaM}$ on mitochondria.

Time courses of changes in TMRE (A), calcein (B), and DCF (C) signals by CaM with or without SR $\mathrm{Ca}^{2+}$. Permeabilized myocytes were perfused with $\mathrm{CaM}(\mathbf{\square} ; 10 \mathrm{nM}, \mathrm{n}=5-15)$ in a nominally $\mathrm{Ca}^{2+}$-free $\left(\left[\mathrm{Ca}^{2+}\right]_{\mathrm{c}}=0 \mathrm{nM}\right)$ internal solution. To diminish SR $\mathrm{Ca}^{2+}$, thapsigargin (TG; $\boldsymbol{\Delta}, 10 \mu \mathrm{M}, \mathrm{n}=8-16$ ) was applied for 15 min before the perfusion of CaM. Data are presented as the percentages of TMRE or calcein intensity or multiples of DCF intensity before CaM application, and values are means \pm SEM. ${ }^{*} \mathrm{p}<0.05$ vs CaM, by two-way ANOVA and Bonferroni test. 

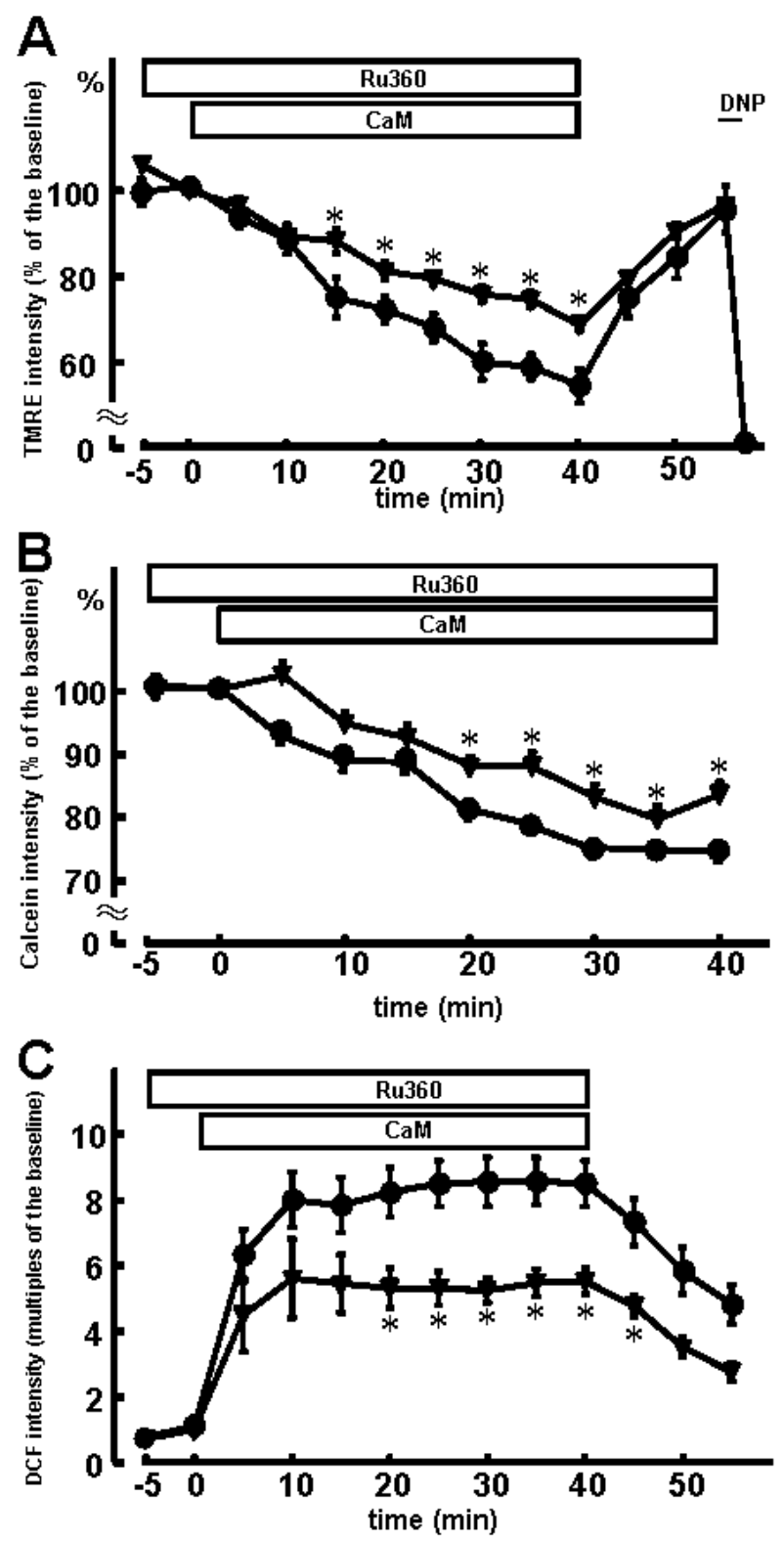

Figure 6 Mitochondrial $\mathrm{Ca}^{2+}$ uptake and the effects of $\mathrm{CaM}$ on mitochondria.

(A), (B), and (C) Time courses of changes in TMRE (A), calcein (B) and DCF (C) signals by CaM with or without an inhibitor of mitochondrial $\mathrm{Ca}^{2+}$ uniporter, Ru360. CaM $(10 \mathrm{nM})$ was perfused in the $177 \mathrm{nM} \mathrm{Ca}^{2+}$ internal solution $(\bullet$, $\mathrm{n}=9-15)$. Cells were pretreated with Ru360 $(10 \mu \mathrm{M})$ for $5 \min (\mathbf{\nabla}, \mathrm{n}=9-11)$, and then CaM was perfused in the presence of Ru360. Data are presented as the percentages of TMRE or calcein intensity or multiples of DCF intensity before $\mathrm{CaM}$ application, and values are means $\pm \mathrm{SEM}$. ${ }^{*} \mathrm{p}<0.05$ vs CaM, by two-way ANOVA and Bonferroni test. 


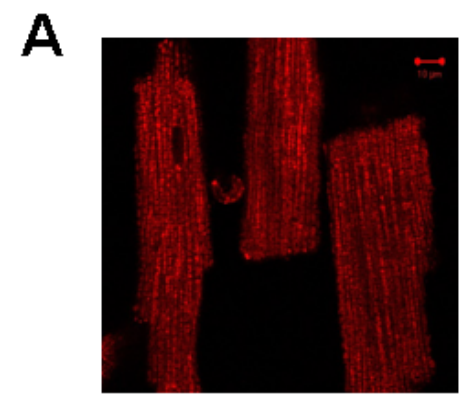

CaM (-)

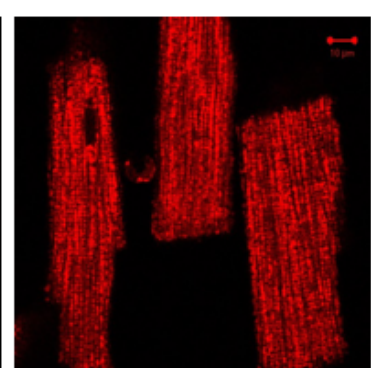

CalM (+)

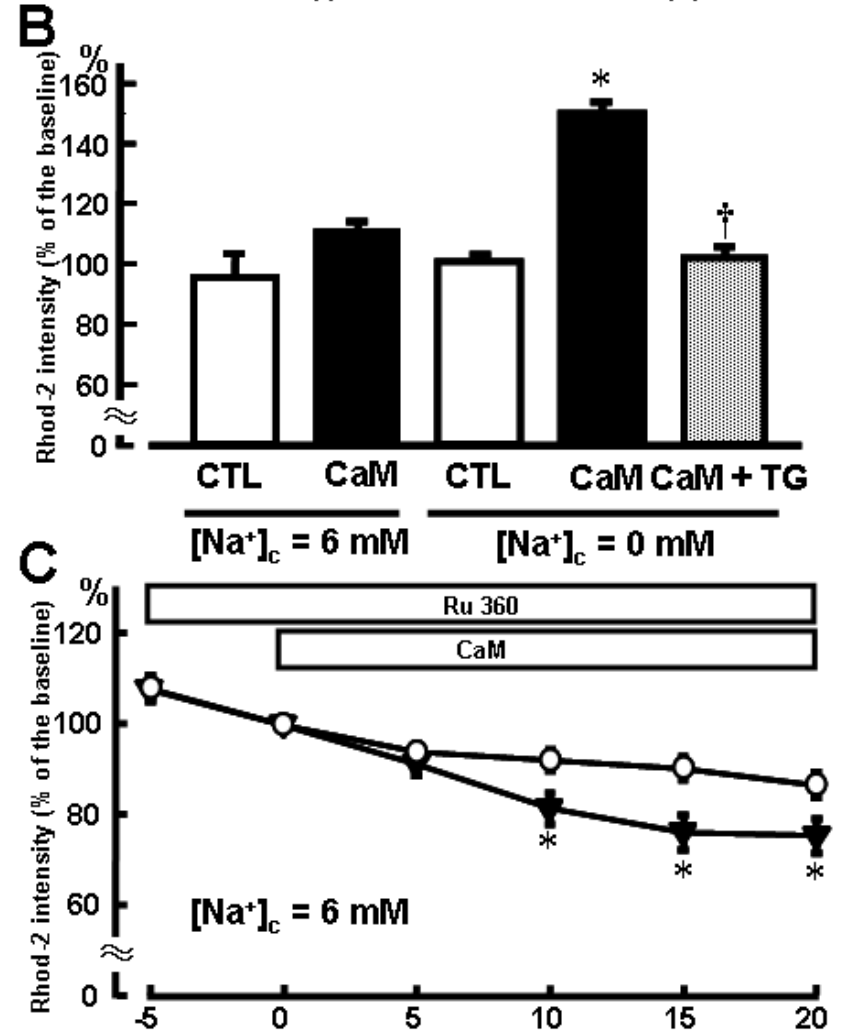

Figure 7, CaM and mitochondrial $\mathrm{Ca}^{2+}$ concentration

(A) The 2-D images of rhod-2, Left; before and right; after the application of CaM in a Na ${ }^{+}$-free $\left(\left[\mathrm{Na}^{+}\right]_{\mathrm{c}}=0 \mathrm{mM}\right.$, $\left[\mathrm{Ca}^{2+}\right]_{\mathrm{c}}=177 \mathrm{nM}$ ) internal solution. (B) The summarized data of the changes in rhod-2 intensity after $20 \mathrm{~min}$ perfusion of $\mathrm{CaM}(10 \mathrm{nM})$. CaM was applied in the control internal solution $\left(\left[\mathrm{Na}^{+}\right]_{\mathrm{c}}=6 \mathrm{mM},\left[\mathrm{Ca}^{2+}\right]_{\mathrm{c}}=177 \mathrm{nM}\right)$ or in a Na ${ }^{+}$-free $\left(\left[\mathrm{Na}^{+}\right]_{\mathrm{c}}=0 \mathrm{mM},\left[\mathrm{Ca}^{2+}\right]_{\mathrm{c}}=177 \mathrm{nM}\right)$ internal solution, where mitoNCX was inhibited. In addition to the mitoNCX inhibition, some cells were perfused with TG to eliminate $\mathrm{SR} \mathrm{Ca}^{2+}$ releases $(\mathrm{CaM}+\mathrm{TG})$. Data are presented as the percentages of rhod- 2 intensity before CaM application, and values are means \pm SEM. $*$ p $<0.05$ vs a $\mathrm{Na}^{+}$-free internal solution, $\uparrow \mathrm{p}<0.05$ vs $0 \mathrm{Na}$ plus CaM by two-way ANOVA and Bonferroni test. (C) Time courses of changes in rhod-2 intensity during perfusion of Ru360 in the absence $(O, n=6)$ or presence $(\boldsymbol{\nabla}, n=6)$ of CaM $(10$ $\mathrm{nM})$. Cells were pretreated with Ru360 for $5 \mathrm{~min}$, and then exposed to CaM. Data are presented as the percentages of the baseline rhod-2 intensity, and values are means \pm SEM. * $\mathrm{p}<0.05$ vs CaM, by two-way ANOVA and Bonferroni test. 


\section{Figure legends for supplemental data}

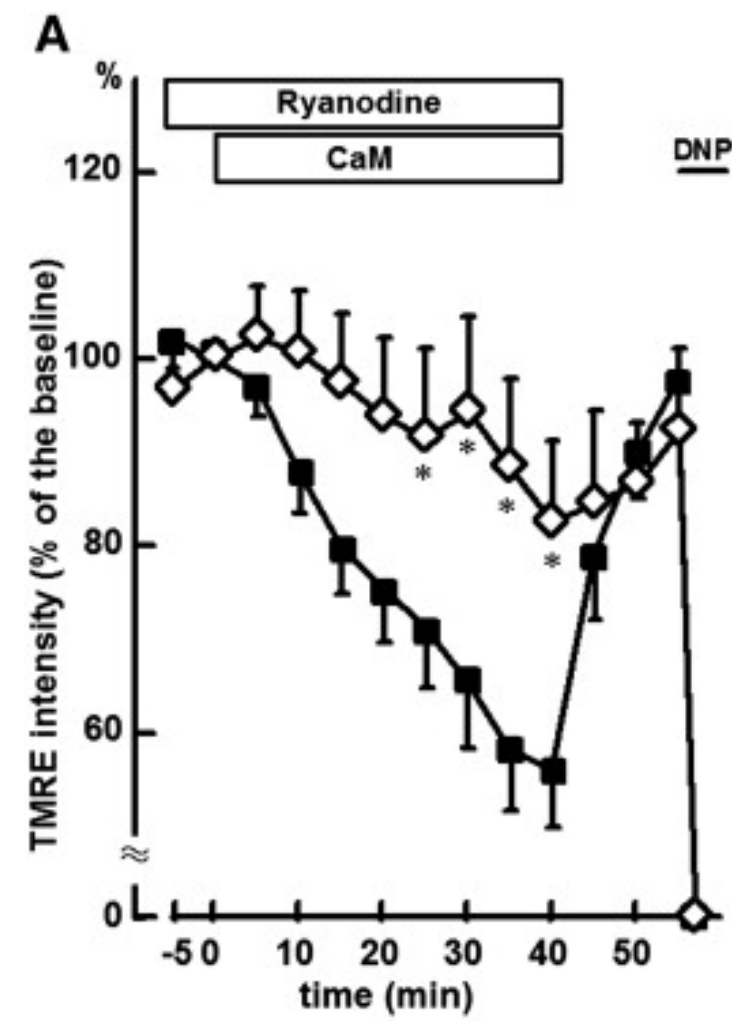

B

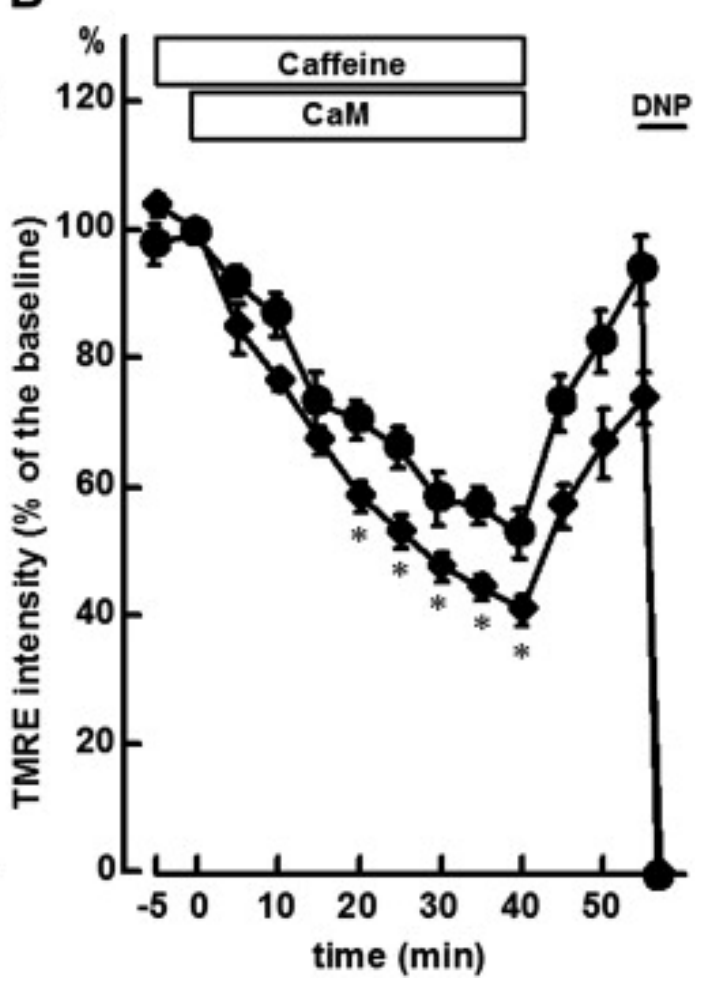

Supple Figure 1, Ryanodine inhibited while caffeine enhanced the effects of CaM on mitochondrial membrane potential.

(A) Time courses of the changes in TMRE intensity during the perfusion of $\mathrm{CaM}(\mathbf{a} ; 10 \mathrm{nM}, \mathrm{n}=16)$, and $\mathrm{CaM}$ plus ryanodine $(\diamond ; 100 \mu \mathrm{M}, \mathrm{n}=5)$ in the $\mathrm{Ca}^{2+}$-free $\left(\left[\mathrm{Ca}^{2+}\right]_{\mathrm{c}}=0 \mathrm{nM}\right)$ internal solution. In the rynanodine-treated group, cells were pretreated with rynanodine for $5 \mathrm{~min}$, and then CaM was applied in the presence of ryanodine. (B) Time courses of the changes in TMRE intensity during the perfusion of $\mathrm{CaM}(\bullet ; 10 \mathrm{nM}, \mathrm{n}=16)$, and CaM plus caffeine $(\diamond ; 1 \mathrm{mM}, \mathrm{n}=6)$ in the $177 \mathrm{nM} \mathrm{Ca}^{2+}$ internal solution. In the caffeine-treated group, cells were pretreated with caffeine for $5 \mathrm{~min}$, and then CaM was applied in the presence of caffeine. Data are presented as the percentages of calcein intensity before CaM application, and values are means \pm SEM. $* \mathrm{p}<0.05$ vs $\mathrm{CaM}, \uparrow \mathrm{p}<0.05$ vs control by two-way ANOVA and Bonferroni test. 


\section{A}

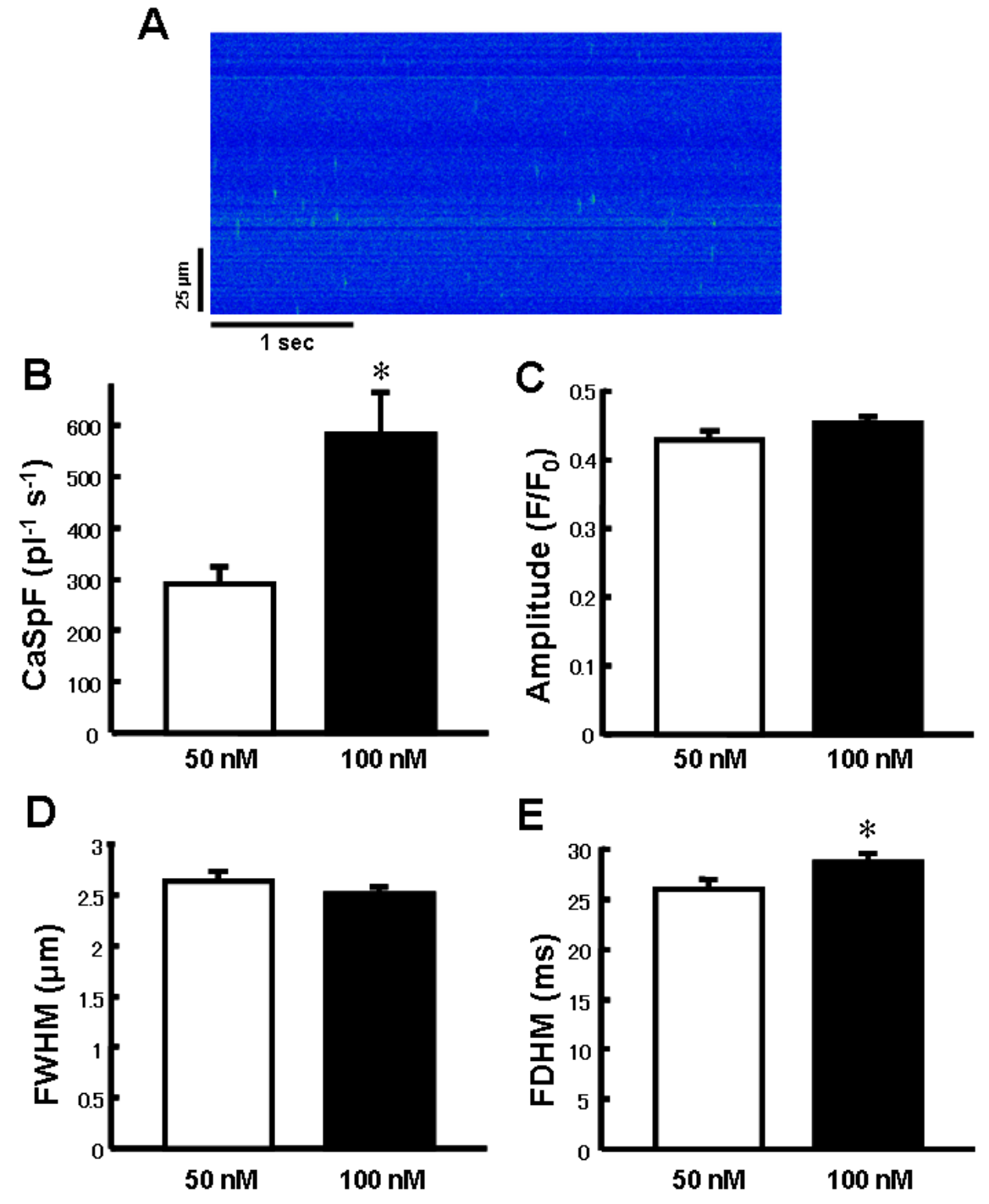

Supple Figure 2, $\mathrm{Ca}^{2+}$ sparks in permeabilized myocytres.

(A) The line-scan image of resting $\mathrm{Ca}^{2+}$ sparks in permeabilized myocytes. Saponin-permeabilized myocytes were perfused with an internal solution, which contained $50 \mathrm{nM} \mathrm{Ca}^{2+}$. (B) $\mathrm{Ca}^{2+}$ spark frequency (CaSPF) in an internal solution with $50 \mathrm{nM} \mathrm{Ca}^{2+}$ (open bars; $50 \mathrm{nM}, \mathrm{n}=5$ cells) or $100 \mathrm{nM} \mathrm{Ca}^{2+}$ (solid bars; $100 \mathrm{nM}, \mathrm{n}=6$ cells). CaSPF $\left(\mathrm{pl}^{-1} \cdot \mathrm{s}^{-1}\right)$ was expressed as the number of $\mathrm{Ca}^{2+}$ sparks per line-scan image after normalization spatially (per pico-liter) and temporally (per second). (C) - (E) characteristics of $\mathrm{Ca}^{2+}$ sparks, (C) The amplitude (difference between peak spark fluorescence and background fluorescence, $\Delta \mathrm{F} / \mathrm{F} 0$ ) of Ca sparks, (D) The full-width half-maximum (FWHM) of Ca sparks, (E) The full-duration of half maximum (FDHM) of $\mathrm{Ca}^{2+}$ sparks. Two different buffered resting $\left[\mathrm{Ca}^{2+}\right]_{\mathrm{c}}$ (open bars; $50 \mathrm{nM}, \mathrm{n}=84$ sparks, and solid bars; $100 \mathrm{nM} \mathrm{n}=194$ sparks) were used. The detection and analysis of $\mathrm{Ca}^{2+}$ sparks were performed using SparkMaster, a program for automated $\mathrm{Ca}^{2+}$ spark analysis. Values are means \pm SEM. $* \mathrm{p}<0.05$ vs $50 \mathrm{nM}$ by unpaired t-test. 